\title{
Factors and Components Affecting Dairy Smallholder Farmers and the Local Value Chain-Kvemo Kartli as an Example
}

\author{
Rami Al Sidawi ${ }^{1, *}$, Teo Urushadze ${ }^{2}$ and Angelika Ploeger ${ }^{1}$ \\ 1 Specialized Partnership in Sustainable Food Systems and Food Sovereignty, Faculty of Organic Agricultural \\ Sciences, University of Kassel, 37213 Witzenhausen, Germany; a.ploeger@uni-kassel.de \\ 2 School of Agricultural and Natural Sciences, Agricultural University of Georgia, Tbilisi 0159, Georgia; \\ t.urushadze@agruni.edu.ge \\ * Correspondence: rami.alsidawi@uni-kassel.de; Tel.: +49-055-42981621
}

Citation: Al Sidawi, R.; Urushadze,

T.; Ploeger, A. Factors and

Components Affecting Dairy

Smallholder Farmers and the Local

Value Chain-Kvemo Kartli as an

Example. Sustainability 2021, 13, 5749.

https://doi.org/10.3390/su13105749

Academic Editor: Marc A. Rosen

Received: 17 March 2021

Accepted: 18 May 2021

Published: 20 May 2021

Publisher's Note: MDPI stays neutral with regard to jurisdictional claims in published maps and institutional affiliations.

Copyright: (c) 2021 by the authors. Licensee MDPI, Basel, Switzerland. This article is an open access article distributed under the terms and conditions of the Creative Commons Attribution (CC BY) license (https:/ / creativecommons.org/licenses/by/ $4.0 /)$.

\begin{abstract}
Smallholder farmers are the cornerstone of the livestock sector and an essential element in building and developing the local dairy value chain, critical for developing its local economy. In Georgia, and despite the efforts made since independence from the Soviet Union until now, farmers still face many problems that prevent them from participating effectively in developing the dairy value chain, especially heavy metal pollution that afflicts the study region. This research study refers to smallholder farmers' viewpoints in the Kvemo Kartli region on the dairy production sector and the problems these farmers face. This study also investigates the effect of several factors (ethical factors, traditions, animal welfare, cultural factors, etc.) on the dairy value chain. The convergence model was used in the mixed-method approach's triangular design as a methodology for this research study. As part of the social data, 140 farmers who produce and sell milk and cheese in the Kvemo Kartli region were interviewed. The results showed the influence of the ethical, cultural, and traditional factors in developing the value chain. The results also showed the problems and difficulties small farmers face in rural areas, on the one hand, and the gap between these farmers and governmental and private organisations on the other hand. These results are compared to those of a previous study, where interviews with experts in Georgia's dairy production sector were performed.
\end{abstract}

Keywords: dairy products; value chain; smallholder farmers; food safety; heavy metals; Georgia

\section{Introduction}

Studies indicate that about $75 \%$ of the farms in the world are family farms, as most of them are small family farms. Despite the different development and modernisation policies that each country adopts to advance the agriculture field in all its sectors, smallholder farmers face many challenges at the local and international levels [1].

Smallholders are the backbone of the economy in countries that depend heavily on agriculture. The dairy sector is one of the most important agricultural sectors for smallholder farmers, as it plays a fundamental role in their daily income and self-sufficiency as well as food security [2-6]. If farmers are forced to change their behaviour due to international hygiene standards without suitable governmental solutions to support them, social problems will arise, and economic issues will appear for society. Thus, this may lead to the farmers' abandoning their farms. The resulting consequences may be drastic, which may occur in fundamental changes in the landscape due to the lack of pastoralism and the inadequate supplies and nutritional status of former smallholders [2-7]. The change will also affect the range of goods; for example, instead of traditional Georgian cheese, it will be replaced by the international cheese "type gouda."

In Georgia and most developing countries, milk production depends on smallholder farmers. It also contributes to securing family livelihoods, supporting food and nutrition sovereignty, and maintaining food safety [8-10]. Therefore, smallholder farmers in these countries are considered one of the most important actors in developing the agricultural 
sector. Milk production is an integral part of the small farm economy in Asia and many other countries. It is what provides them with self-sufficiency in terms of food and some cash. For example, smallholder dairy producers in countries such as China and Thailand account for a large part of the economic policies adopted in developing the dairy sector. Many smallholder farmers in these countries have become able to compete and grow their produce [11-13].

On the other hand, there are several countries in which the dairy production sector at the local and international levels is still in the initial stages, and there are continuous attempts to develop and advance it to reach the level and efficiency of local and international standards. In countries such as Georgia, Pakistan, Bangladesh, Mongolia, and others, smallholder farmers mainly contribute to the provision of milk. However, the dairy value chain in these countries is still under development to meet the local requirements of dairy and cheese, and then to try to reach production efficiency with international standards that would help develop this chain [11-13].

However, dairy production growth in developing countries globally results from an increase in the number of animals kept rather than an increase in productivity per head $[10,14]$. The low quality of feed, animal care and disease prevention, the demand of access to markets, and the utilisation of all available services in turn lead to the nondevelopment of the dairy value chain [10].

Dairy production is one of the oldest agricultural sectors in the Kvemo Kartli region in Georgia [15]. The dairy market in Georgia is one of the most important economic sectors in the country; Georgia annually produces approximately 500 million tons of milk [16]. The smallholder farmers are the main and the most important producers of milk. However, smallholder farmers sell milk through informal channels without any health or legal supervision, as most of them do not have the necessary experience to produce milk with safety specifications $[15,16]$.

The collapse of the Soviet Union for Georgian farmers was a huge turning point in every aspect. In the Soviet era, there were collective farms that kept stock of breeds in the dairy sector, but in the post-Soviet period, these farms no longer existed. Small land areas were allocated to all smallholder farmers and provided access to common pastures [17-20].

Nevertheless, because of the civil war and all the economic and political problems and crises that the country suffered from, smallholder farmers mainly adopted diversified subsistence farming, with a few cows or small numbers of other farm animals (such as chickens, sheep, goats, pigs, etc.). They also cultivated some crops to feed livestock and others for personal consumption [19].

At that time, the economic conditions were deplorable, so small farmers relied on producing milk and selling it in the local market in their villages or sending it to Tbilisi with a third person, earning some money to barter this milk for other food products $[19,21,22]$. Non-cash exchange trading became very popular, for example, exchanging cheese for hay.

It also appeared that farmers sent their livestock daily with the village herds to the pastures; the shepherd supervised them. Thus, there was no supervision or control over the reproduction of this livestock or the bulls' quality. As local breeds of adapted and unimproved cows increased, there was limited potential to improve productivity in the dairy and meat sector $[19,23]$.

At the time of the collapse of the Soviet Union, the available veterinary services collapsed, including all the other services that were provided for money despite their low quality and poor value. The relationship between farmers and veterinarians was damaged, as there was a lack of trust in all parties' services [19]. The changes that occurred during the collapse of the Soviet Union and afterwards in Georgia affected women in particular, as the responsibility for livestock farming, cleaning and feeding the animals, and milking the livestock was the women's share, including processing dairy products and making cheese $[19,24]$.

Women had enough experience at that time to know if disease had afflicted any of the livestock, and they were also able to diagnose these symptoms and order the necessary 
medicines. However, in the pre-and post-Soviet era, women were suffering from limited freedom in society due to social and cultural reasons. As men were doing all the work outside the home, women had limited access to any new information or development in agriculture and livestock $[19,24,25]$.

In the past few years, and during the reforms being undertaken by the country, the Georgian economy was in an essential stage of transformation [26], and especially after 2004, intensive work was done on developing concepts and methods of working economic strategies and deepening the concept of economic liberalisation [21]. Despite this, small farmers who live in rural areas still depend on dairy products. They use the state's pastures for grazing and send their livestock to mountain grazing areas accompanied by the shepherd in the summer season, informally. They depend heavily on hay in the winter [22,27].

This study is considered part of several research pieces, some of which have been published [28,29], which delved into experts' opinion in developing the dairy value chain in Georgia and farmers' perception regarding water quality and risks in the Mashavera River Basin in the Kvemo Kartli area.

As several studies also dealt with water and soil analyses in the Kvemo Kartli region in Georgia, this region suffers significantly from heavy metal pollution. Therefore, this research aims to determine the problems that farmers suffer from on the ground and the extent to which food safety systems are applied and compare them with experts' opinion.

\subsection{Socio-Cultural Factors}

The citizens' concept of sustainability in the livestock sector illustrates the critical and fundamental role of values. For many, especially smallholder farmers, sustainability is a socio-cultural concept of livestock production systems [30]. In Ethiopia or the Netherlands, for example, the socio-cultural aspect plays a critical role. Production is not the only goal of the dairy sector, but several considerations must be taken into account, such as the connection of dairy and cheese production to the national or agricultural culture and the technology used for production, which may differ according to different cultures and traditions [30,31]. For Azerbaijan, Armenia, and Georgia, the socio-cultural concept was greatly important, especially in the transition period [32].

The dependence of smallholder farmers in Georgia on producing milk is substantial. The production and sale of milk and the manufacturing of many types of cheeses are still the cornerstones of Georgian society and Georgian culture [33]. However, producing highquality milk requires technical skills and accurate knowledge for every dairy value chain step. Despite their extensive and ancient experience in milk production and its derivatives, farmers in Georgia face many problems represented in the lack of training and failure to keep pace with modern technology and the inability to control the market $[33,34]$. For example, the increase in the import of powdered milk, and the increase in the demand for it by large dairy producers, negatively affected small farmers. In 2016, the import of milk powder reached 8.34 tons, compared to 2017, when it increased to nearly 9862 tons $[33,35]$.

Farmers, relying on their ancient culture and traditions, do not see that self-managed animal feed is necessary to feed their livestock. They depend entirely on pastures, as some practices still exist even after the Soviet Union's collapse, e.g., farmers grazing their livestock together [23]. Farmers send their cows with a shepherd to feed on the pastures, or the peasants take turns doing that daily, but if the farmer is unable to do so, he hires a shepherd to do this task [23].

As farmers who do not have the time or ability to take care of their livestock, they sometimes rent their cows to other farmers or milk production companies that pay them in cash or give them in return products such as cheese or butter [23]. The old norms of dealing between farmers and milk collectors still exist, as all that is agreed upon is verbally between the two parties, and the payment process for farmers is either weekly or every two weeks. However, some farmers prefer advance payments for other needs. The milk collectors sometimes depend on giving the farmers some of what they need (such as fodder, 
for example) and thus deduct the feeding cost from the final amount to be paid to the farmer in exchange for milk [23]. These traditions, which depend on the ancient peasant culture, still dominate Georgian society in the countryside to a large extent and build a steady bridge of trust between farmers and milk collectors [36].

Religious culture also has a significant role in Georgia, and it also affects the demand for dairy products. As the majority of Georgians are Orthodox Christians, the rates of demand for dairy products decrease during fasting periods; thus, prices are significantly affected by this, as farmers are affected automatically during this period. In the postfasting period, the demand for these products increases dramatically, and consequently, the pressure on prices increases, which directly affects farmers [23].

\subsection{Socio-Demographic and Socio-Economic Factors}

Socio-demographic factors such as gender, family, and language, socio-economic statuses such as income, education, employment, and locality or living area are essential vital factors that directly affect farmers and the existing agricultural economic system [37-40].

According to the Eurostat report in 2019, the National Statistics Office of Georgia (Geostat) follows the international standards in labour market statistics. Still, there are some exceptions; in Georgia, farmers who produce goods for their consumption are classified as workers. The percentage of these people is considerable, which directly contradicts the International Labour Organization (ILO) concept, as the rate of employment in Georgia is overestimated. In return, there is a low rate of unemployment compared to other countries [41].

Figure 1 shows the difference in the population between urban and rural areas in Georgia. It shows that the proportion of the rural population has decreased since 1926, reaching 41.0 in 2020 compared to previous years [42,43].

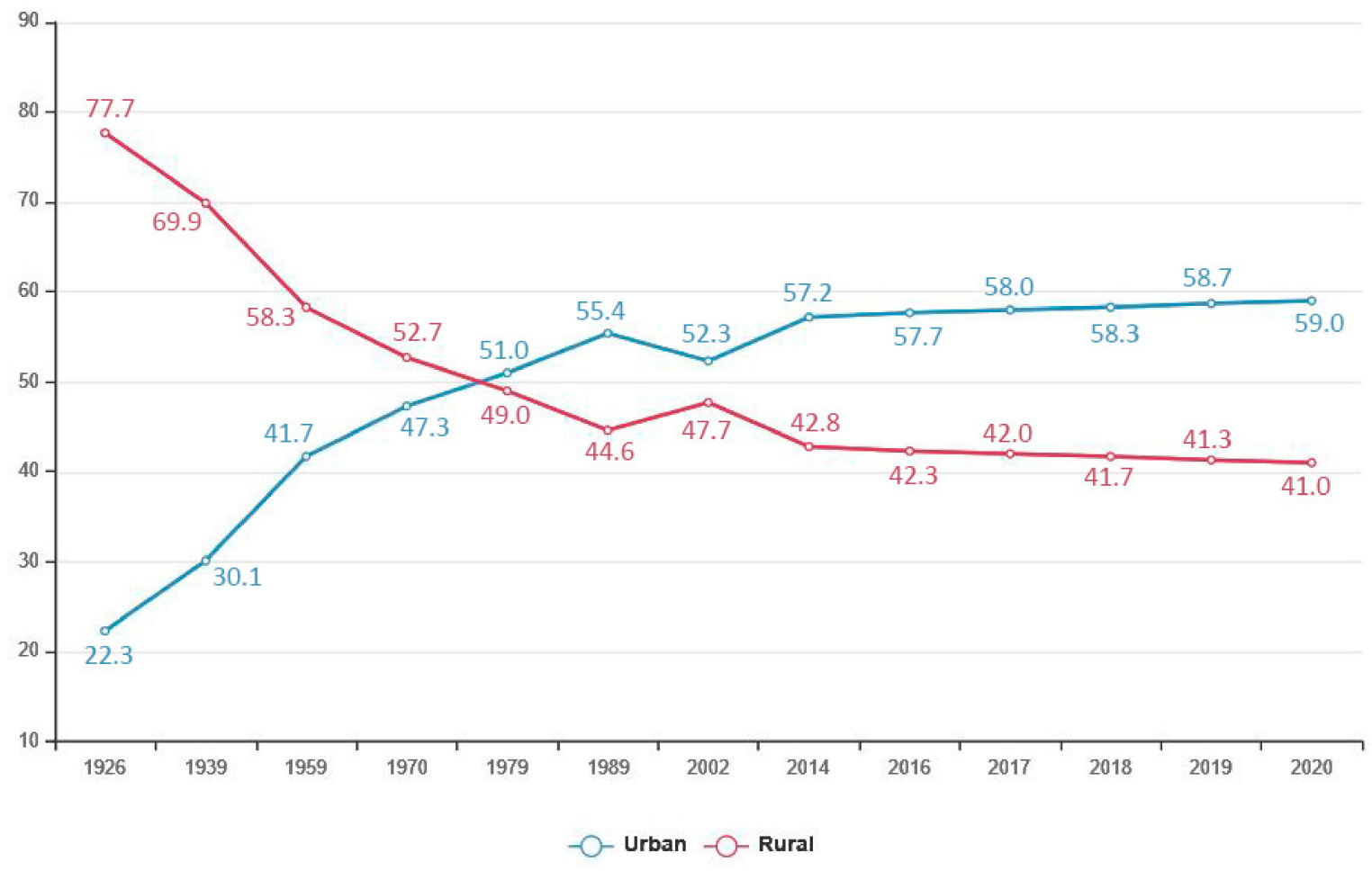

Figure 1. Distribution of the Georgian population (\%) in urban and rural areas [29,30].

Based on the Geostat report 2016, the number of populations in the Kvemo Kartli region has decreased significantly compared to the 2002 census, dropping to $14.6 \%$ compared to the capital Tbilisi people, which increased by $2.5 \%$ [44]. 
As Georgia has undergone massive changes since the collapse of the Soviet Union and its conflicts, many constructive initiatives and programs have emerged that help develop the countryside and support smallholder farmers $[17,18,45,46]$.

The government promoted women in rural areas, provided the necessary support for them in agricultural businesses and cooperatives, and supported their participation in industry and their inclusion in local decision-making bodies $[47,48]$. Based on the IFAD report in 2018, rural women's access to information, available services, and decisionmaking are much lower compared with men in Georgian agrarian society. Therefore, according to the United Nations Global Gender Gap Index, Georgia is ranked 90 out of 144 countries [47]. The average male income in Georgia's agricultural sector is 25 per cent higher than that of women, as women own only about 31 per cent of the farms, which is almost a quarter of the farms owned by men [47].

The access of farmers in rural areas to and control of the market is complicated, especially with respect to climate change. Smallholder farmers face new risks, but they do not have sufficient knowledge of adaptive measures and cannot afford them. This development represents a new threat that may threaten rural areas [47,49].

Based on the Geostat report in 2019 (Table 1), the farmers' share of the sale of agricultural products concerning the household's total income decreased in 2019 to 5.5\% compared to $6.4 \%$ in 2016 [43].

Table 1. Farmers share of agricultural products from the total income of the household (\%) [30].

\begin{tabular}{ccccc}
\hline Year & $\mathbf{2 0 1 6}$ & $\mathbf{2 0 1 7}$ & $\mathbf{2 0 1 8}$ & $\mathbf{2 0 1 9}$ \\
\hline Share of income (\%) & 6.4 & 4.7 & 5.5 & 5.5 \\
\hline
\end{tabular}

All these factors subject Georgia dairy production to significant challenges: the decline in the population in rural areas, the increase in poverty, and the loss of dynamism and entrepreneurship in those areas with a rise in the emigration of young people and a small number of retirees, who depend for their livelihoods on remittances, as well as social transfers and subsistence farming [35,47].

\subsection{Ethical Factors}

The Georgian society relies heavily on animal products and, in particular, on dairy products [22]. The demand for these products increased in the past years, and this massive increase in production raised a wide range of ethical issues. One of the most important of these issues is the concern for animal welfare [50].

Consumer awareness of food quality and safety has increased dramatically, as animal products' ethical factor has played a significant role in consumer behaviour [51,52]. On the other hand, dairy producers, retailers, and the food industry are demanding higher standards for animal welfare to obtain superb quality, which supports the economy on the one hand and maintains food safety and food security standards on the other hand [50]. All this prompted small farmers and large landholders to think about the safety and welfare of the animals.

Animal welfare is a complex subject that differs from one culture to another. It is a subject that has scientific, cultural, social, ethical, religious, and political dimensions. Providing safe food for people depends on the health and productivity of these animals [50]. For example, the state legislation that aims to support animal welfare in farmers' opinions is not entirely fair from a political perspective. The increase of such laws creates a feeling of insecurity among farmers and undermines confidence in the political decision $[26,33,50]$.

Regarding traditions, studies have shown that rural farmers have a common understanding of the cultural, political, economic, and social context of what it means to be a good farmer. Therefore, modern financial plans and legislation aimed at developing the dairy sector and increasing interest in animal welfare are considered by many farmers as a threat because this contradicts their culture and deep-rooted traditions $[26,33,50,53]$. 
Besides, these farmers' experience is also a significant factor, especially in the ethical matter. Political decisions, which aim to increase farmers' awareness and knowledge, play a major role in creating a communication bridge between them and the responsible parties [33,50]. As a result of all the circumstances that Georgia went through, from the collapse of the Soviet Union to the internal problems that the country suffered from, small farmers were and still face many issues in the dairy production sector [26]. The lack of fodder and the limited pastures available for grazing cows are among the most critical problems facing farmers. The lack of adequate shelter for animals or places prepared for them in terms of health in rural areas increases the dangers that animals suffer [53]. The farmer's use of antibiotics in animal foods is due to the lack of health care caused by the lack of veterinarians $[54,55]$. The human consumption of these dairy products and milk may generate diseases and resistance that may be transmitted to farmers and threaten their safety and health $[54,55]$.

In an attempt by small farmers to take care of the animals and in an effort to increase the quality of the dairy products, families owning many cows are trying to secure enough food from the grass in the summer and wheat, corn, and straw in the winter, despite the high prices of these materials, and to keep pace with animal welfare regulations [33,53]. In the Kvemo Kartli region, most farmers own a small number of cows with low productivity. Thus, securing the necessary fodder may be a problem for them compared to those with extensive holdings [53].

\section{Methodology}

\subsection{Study Area}

The research study was conducted in southeastern Georgia in the Kvemo Kartli region (see Appendix A, Figures A1 and A2). A survey on smallholder farmers' dairy production was completed in eight villages in Summer 2019 (Figure 2) in the Bolnisi and Dmanisi municipalities (Chapala, Vanati, Bolnisi, Mtskneti, Sabereti, Ratevani, Kazreti, and Kvemo Bolnisi).

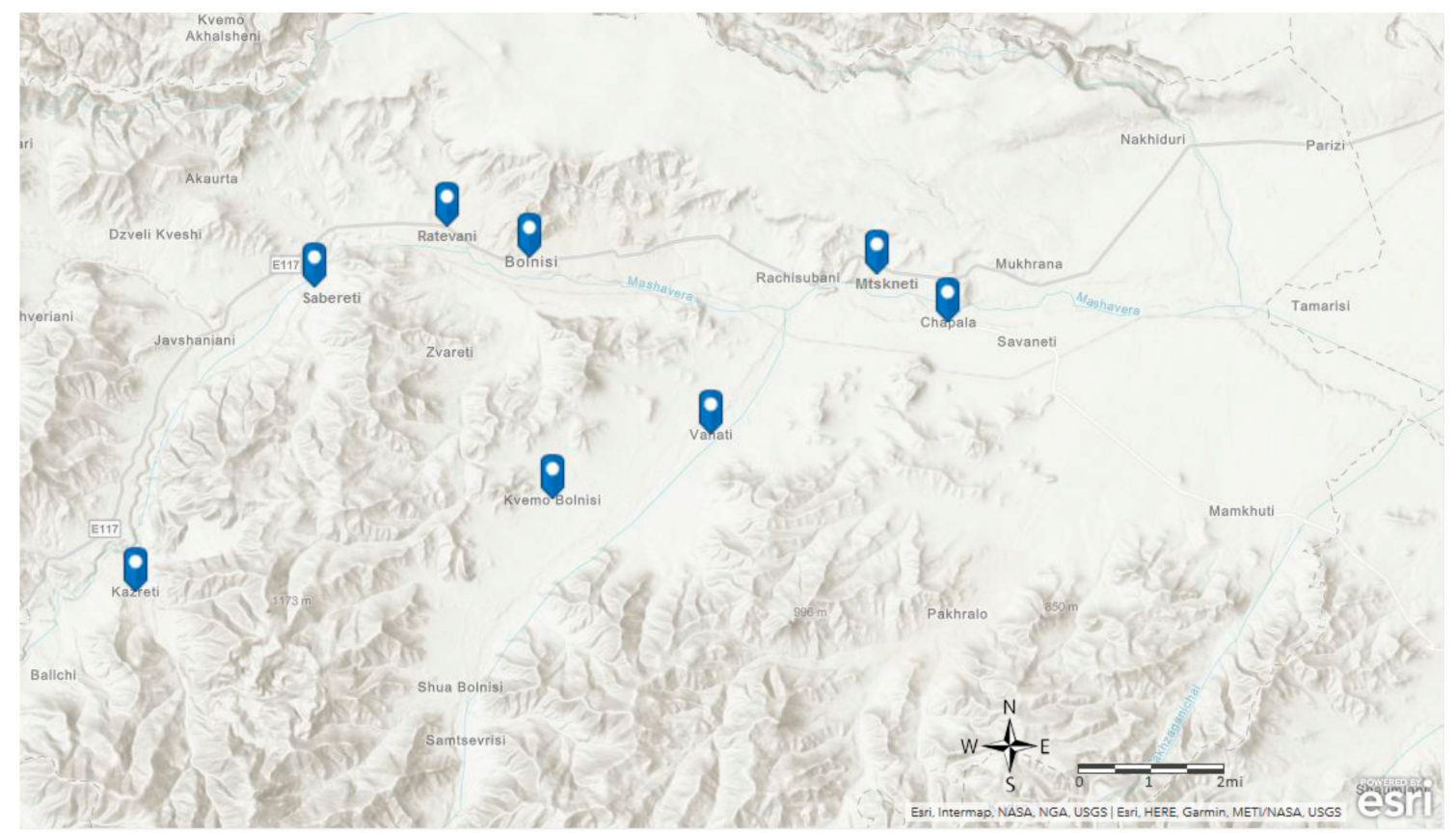

Figure 2. Map of the study area (Authors' illustration); ArcGIS Pro Data sources: Base map layer; ESRI satellite (ArcMap).

The Kvemo Kartli region of Georgia is considered the largest beef producer in the country and is close to the capital, Tbilisi. The primary source of income for families in this region depends on livestock, cattle, and sheep. According to Geostat statistics 2019 [56], 
the Kvemo Kartli region has holdings oriented mainly on livestock production (18.4 per cent), which is the highest percentage compared to the rest of Georgia's regions. The total population of Kvemo Kartli is 434.2 people. In comparison, 244.5 inhabitants live in rural areas [43].

The total number of smallholder farmers in the Kvemo Kartli region is unknown. Many families do not depend on agriculture or raising cows or other husbandry animals in their living. However, they own a small number of cows and do officially sell their milk as raw milk or as homemade cheese. For this reason, it is difficult to know the actual number of farmers working in this field until now.

Smallholder farmers suffer from several problems, for example, the absence of modern agricultural machinery, the difficulty of accessing the local and international markets, the lack of knowledge of the current developments in the dairy markets and their production methods, and the problem of accessing veterinarians. Despite all these difficulties and challenges, producing good quality meat and dairy products is a growing market in Georgia.

\subsection{Mixed Method Approach}

This study relied on the convergence model in the tripartite design of the mixedmethod approach. The use of a mixed-method design allows questionnaires or surveys and interviews to be conducted together [57].

As shown in Figure 3, we used the experimental design of qualitative and quantitative surveys and interviews as primary data. Data and information for the dairy sector in Georgia were approved as supporting data. The results of the interviews with dairy experts have been published [57]. This publication aims to present a quantitative survey with Georgian farmers and discuss the factors given expert opinions.

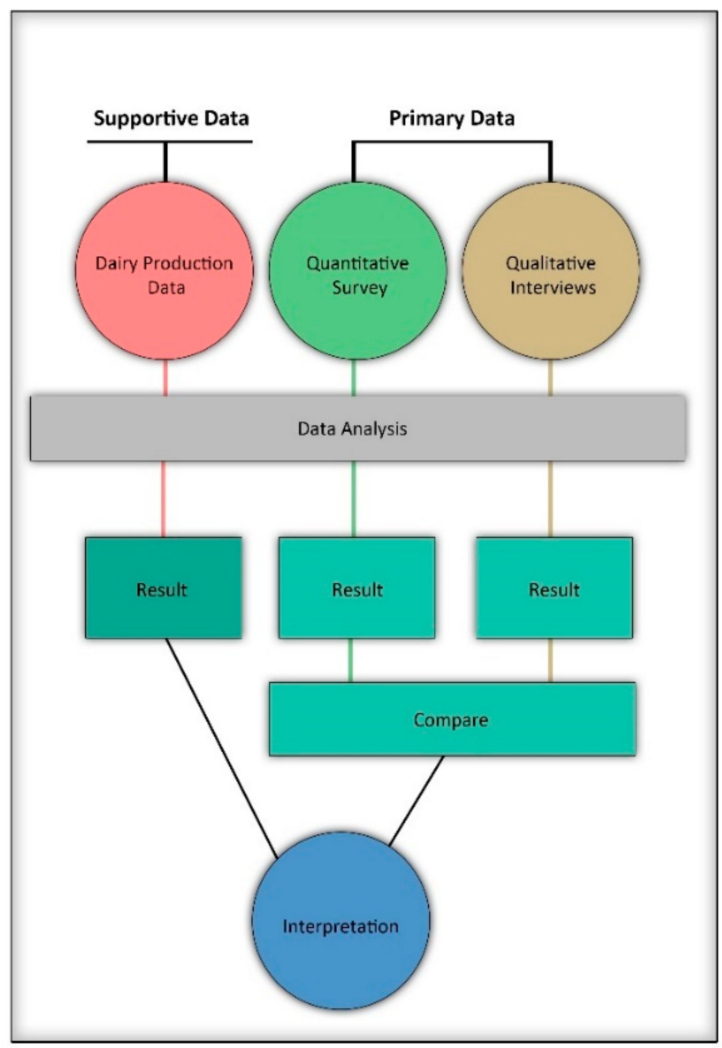

Figure 3. Study-method design (Adaption from Creswell and Clark (2006)). 


\subsection{Survey and Data Collection}

All data used in this study were collected through a survey conducted in Georgia's Kvemo Kartli region. We collected these data from eight villages in June 2019. These villages were chosen based on our previous research, which showed heavy metal pollution in water, soil, and plants. We wanted to get in close contact with the smallholder farmers who live in this region and know the problems occurring in the area and their adherence to food safety standards in dairy production.

When we entered these villages, we did not establish any particular criteria to select the farmers whom we wanted to interview. Most farmers are not very welcoming to strangers, especially those who gather information, because they think they work for the government. Besides, these regions are known for having multiple nationalities. There are Georgians, Azerbaijan's, and a few Russians. Therefore, field trips were carried out to meet all the difficulties facing us.

The questionnaire was based on open and closed questions. All participants in this survey are smallholder farmers who depend for their livelihoods on raising livestock as a primary income or secondary income and on subsistence farming. The questions were arranged logically and interconnected with each other depending on the aim of this research. All interviews were face-to-face, and all these questionnaires were filled out during the interviews. Table 2 shows that the questionnaire was based on several factors (see Appendix A. Table A1), the most important of which are demographic and geographic factors, Georgian traditions, social and economic factors, and the ethical factor.

Table 2. The coded data and descriptive statistical analysis $(\mathrm{N}=140)$.

\begin{tabular}{|c|c|c|}
\hline Domains and Variables & Category (Coded) & $\%$ \\
\hline \multicolumn{3}{|c|}{ Upstream (Input Supplies) } \\
\hline \multicolumn{3}{|c|}{ Sociodemographic/Socio-Geographic } \\
\hline \multirow{8}{*}{ Village } & Chapala & 20 \\
\hline & Vanati & 7.1 \\
\hline & Bolnisi & 15 \\
\hline & Mtskneti & 13.6 \\
\hline & Sabereti & 6.4 \\
\hline & Ratevani & 13.6 \\
\hline & Kazreti & 12.1 \\
\hline & Kvemo_Bolnisi & 12.1 \\
\hline \multirow{2}{*}{ Gender } & Male & 75 \\
\hline & Female & 25 \\
\hline \multicolumn{3}{|c|}{ Household socio-economic background } \\
\hline \multirow{2}{*}{ Size of the household } & Up to four members & 46.4 \\
\hline & More than four members & 53.6 \\
\hline \multirow{3}{*}{ Animal housing } & Small barn with other animals & 41.4 \\
\hline & Separate barn without other animals & 17.1 \\
\hline & Outside small open barn with other animals & 41.4 \\
\hline \multirow{2}{*}{ Dairy production or animal husbandry is the only financial income } & Yes & 12.9 \\
\hline & No & 87.1 \\
\hline
\end{tabular}


Table 2. Cont.

\begin{tabular}{|c|c|c|}
\hline Domains and Variables & Category (Coded) & $\%$ \\
\hline \multicolumn{3}{|c|}{ On-farm (production) } \\
\hline \multicolumn{3}{|c|}{ General } \\
\hline Started the dairy farm & More than 20 years ago & 100 \\
\hline Basic knowledge of dairy farming & Yes & 100 \\
\hline \multirow{3}{*}{ Reasons for starting dairy farming } & Income & 12.9 \\
\hline & Own consumption & 32.1 \\
\hline & Both & 55 \\
\hline \multicolumn{3}{|c|}{ Dairy farm structure, facilities, and management } \\
\hline \multirow{5}{*}{ Other livestock on the farm } & Hen & 65 \\
\hline & Sheep & 10 \\
\hline & Goat & 5 \\
\hline & Calf & 17.1 \\
\hline & Pigs & 20 \\
\hline \multirow{5}{*}{ Number of cows } & 1-3 Cows & 57.1 \\
\hline & 4-7 Cows & 22.1 \\
\hline & 8-11 Cows & 7.9 \\
\hline & 12-15 Cows & 7.9 \\
\hline & More than 15 Cows & 5 \\
\hline \multirow{5}{*}{ Responsibility on the animals/farm } & Wife, only & 36.4 \\
\hline & Husband, only & 2.9 \\
\hline & Wife and children & 12.9 \\
\hline & Husband and wife & 20 \\
\hline & More than two family members & 27.9 \\
\hline \multirow{4}{*}{ Animal breed } & Local breed & 23.6 \\
\hline & Georgian mountain breed & 2.1 \\
\hline & Both & 7.1 \\
\hline & No idea & 67.1 \\
\hline Cows for milk and meat purposes & Yes & 100 \\
\hline
\end{tabular}

\begin{tabular}{lcc}
\hline & Labour use in dairy farming & \\
\hline \multirow{2}{*}{$\begin{array}{c}\text { Responsibility for feeding, cleaning, milking, and processing as well as } \\
\text { marketing }\end{array}$} & One person & Two people \\
\cline { 2 - 3 } & More than two people & 29.3 \\
\hline
\end{tabular}

Feeding

Type of grazing for dairy animals

Free grazing (in the pasture) between March

to August and no grazing between 95 September to February

\begin{tabular}{cc} 
September to February & \\
\hline Other & 5 \\
\hline Grass & 100 \\
\hline Hay & 70 \\
\hline Corn & 33.6 \\
\hline
\end{tabular}


Table 2. Cont.

\begin{tabular}{|c|c|c|}
\hline Domains and Variables & Category (Coded) & $\%$ \\
\hline Sending the cows to the mountain in HS * & Yes & 47.1 \\
\hline Enough fodder for dairy animals (for the entire year & Yes & 3.6 \\
\hline Making conserved feed (e.g., hay) & Yes & 3.6 \\
\hline \multirow{2}{*}{ Sources of water are available for animals } & Khrami river & 26.4 \\
\hline & Mashavera river & 73.6 \\
\hline Satisfied with the water quality of the primary water sources & Yes & 60 \\
\hline Water-amount enough for animals (yearly) & Yes & 18.6 \\
\hline \multicolumn{3}{|c|}{ Output (Downstream) } \\
\hline \multirow{4}{*}{ Milk selling point } & Bazar & 42.1 \\
\hline & Small Supermarket & 30 \\
\hline & Collecting point (third person) & 20 \\
\hline & On the road & 17.1 \\
\hline Difficulties selling the milk & Yes & 53.6 \\
\hline \multirow{3}{*}{ Cheese varieties } & Sulguni & 12.1 \\
\hline & Imeruli & 39.3 \\
\hline & Sulguni + Imeruli & 47.9 \\
\hline \multirow{3}{*}{ Cheese for marketing or self-consumption } & Marketing & 4.3 \\
\hline & Self-consumption & 40.7 \\
\hline & Both & 54.3 \\
\hline Milking techniques & With hand & 100 \\
\hline Washing udder before and after the milking process & Yes & 85.7 \\
\hline
\end{tabular}

${ }^{*}$ HS: high season: from March to August.

The survey included 140 smallholder farmers, of whom 105 were males, and 35 were females. These interviews were conducted on the farms in Georgian and Russian languages with the presence of a translator. All farmers were selected randomly. Later, all data were transferred and saved in English. Upon completing the survey, all data for the survey were transferred to an Excel datasheet.

The number of farmers interviewed was not high, but it is sufficient to know the opinions of small farmers in the Kvemo Kartli region of Georgia [58], so the size of these samples does not allow generalisation of the results to all small farmers in Georgia.

As for the following research study, an analysis of raw milk samples and homemade cheese will be performed. These samples were collected from those farmers being interviewed to see whether the milk is contaminated with heavy metals. Recent studies have proven their presence in soil, plants, and drinking water [29].

\subsection{Data Analysis}

As Table 2 shows, all the data were transferred to an excel sheet as coded data, to show the descriptive statistical results for each section of the variables. Age was not considered in this questionnaire because most farmers refused to mention their age, either because of their society's customs or because they did not know their exact birth date.

Because of the importance of animal welfare, animal husbandry places in the survey were divided into three sections (small barn with the other animals, separate barn without other animals, and outside the small open barn with other animals). The questionnaire also led to knowing the source of water used to feed the livestock. The majority of the results were distributed between the Khrami River and the Mashavera River. As previous 
studies indicated, these rivers are polluted with heavy metals [59-63], and farmers are dependent on these river waters as a significant resource (water and grass) for their animals. The factor"type of feed and livestock feeding areas" indicates the validity of the fodder provided to livestock and its sources and whether the farmer depends only on grass or other feed. SPSS version 27.0 (IBM, USA) software was used for all the statistical analyses, where the overall comparison between the survey factors was calculated using Spearman correlations $\left(r_{\mathrm{s}}\right)$. A t-test for independent samples tested whether the means of two independent samples were different. ArcGIS Pro was used to map the study area.

\section{Results and Discussion}

\subsection{The Factors and Components Affecting the Dairy Farmers and Value Chain Development}

\subsubsection{Socio-Demographic Factors}

The results showed that the percentage of male farmers who participated in the survey was higher than the women's share (75\% to $25 \%)$. The questionnaire's demographic characteristics show how Georgian society has been affected by ancient culture and traditions. Women in rural areas still do not have enough freedom or access to the market and follow up on all agriculture developments, especially the dairy production sector. As the questionnaire results show (see Figure 4), women are mainly responsible for the livestock on the farm or at home. They are the ones who milk the cows and prepare the milk for sale or for home use in making cheese or other products. Some of the women we interviewed reveal this situation as:

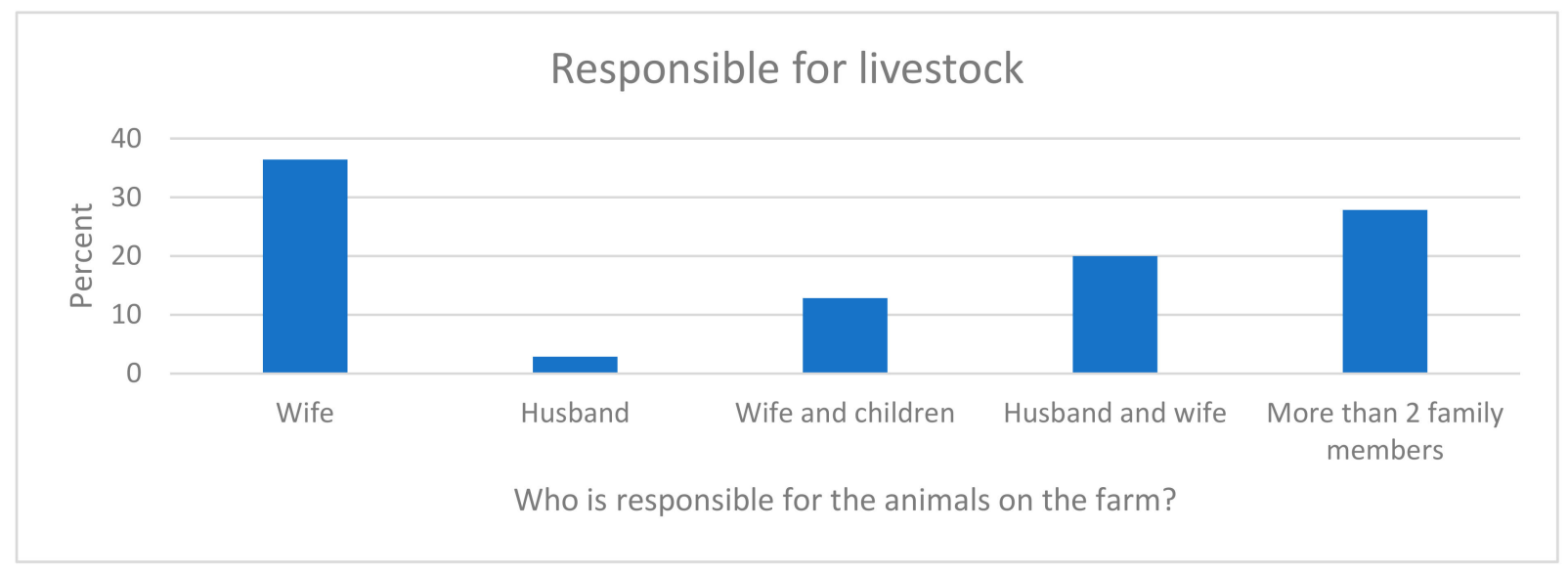

Figure 4. Persons responsible for livestock on smallholder farms in Georgia (N=140, Mean= 28, Std. Dev. = 18,207).

I: "We are the ones who do all the work at home. The men send the cows in the morning to the pastures only, and we are the ones who in the evening collecting the milk and preparing it for sale or to make cheese. This is the hard work and not selling the milk and cheese." (9 June 2019, Chapala).

Other women stated that:

I: "My mom and grandmother did this work in the past; they milked cows and made cheese and prepared it for sale or home consumption. And here we are, doing the same work, nothing has changed." (10 June 2019, Bolnisi).

\subsubsection{Social and Cultural Factors}

Furthermore, Georgian culture and traditions play an important role in rural society and directly influence livestock raising and marketing.

Figure 5 shows that $47.9 \%$ of the smallholder farmers interviewed use a large portion of the milk to make two types of cheese, Sulguni + Imeruli, as these two are among the most consumed types of cheese in Georgia. 


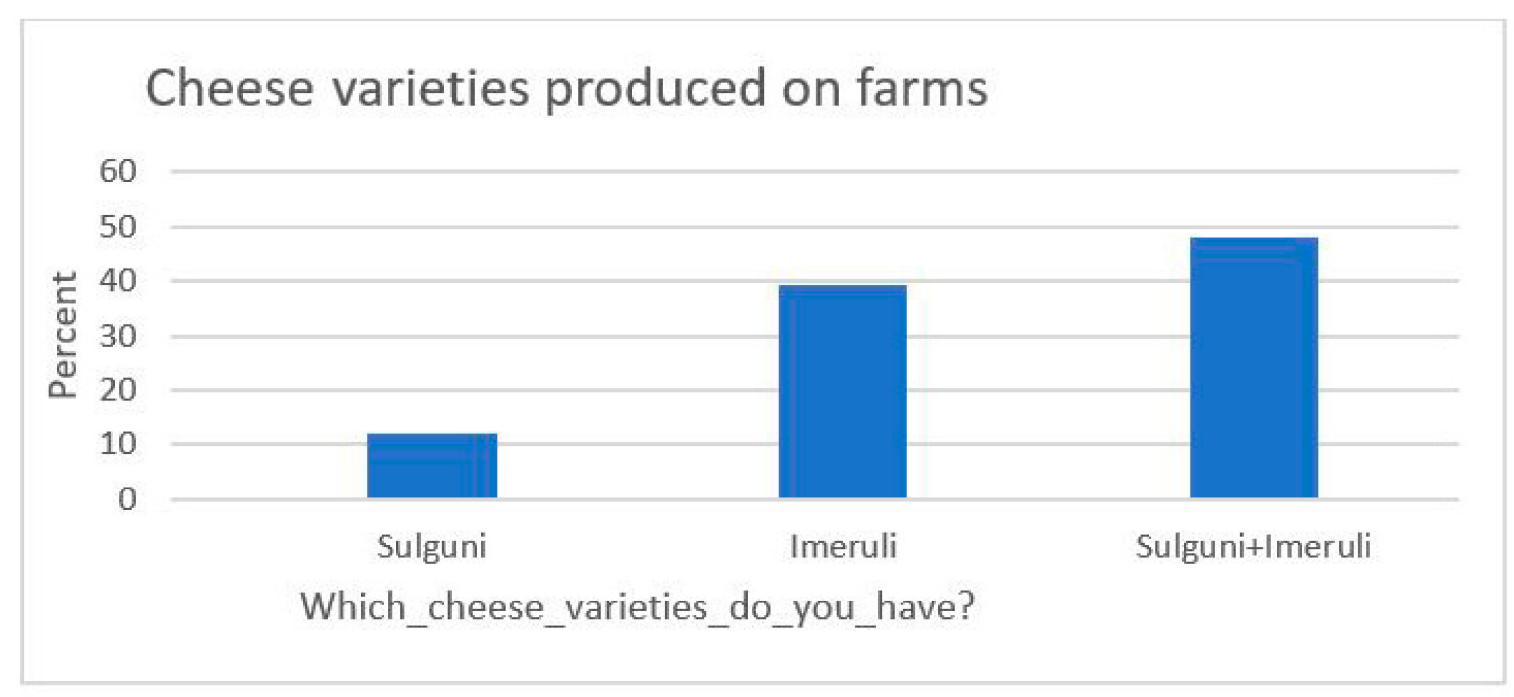

Figure 5. Cheese varieties made on interviewed farms $(\mathrm{N}=140$, Mean = 35, Std. Dev. = 31,112).

Smallholder farmers used to use pastures for grazing cows. It was not their previous habit to manufacture conserved fodder, as the questionnaire showed that $96.4 \%$ of them did not resort to making this fodder (see Table 2).

These results were compared with a previous study we conducted (interview with experts in dairy production in Georgia) [28]. The experts focused on Georgia's culture and traditions in developing the value chain of dairy products, especially in rural areas. It is crucial to take into account the cultural and social background of small farmers. With several reservations, women in rural areas are still the ones who make cheese at home and milk cows. Hygiene standards and food safety measures are rarely applied [28]. They sell the cheese or milk they produce on the streets, in small supermarkets, or the Bazar, and thus it is difficult to monitor them.

Based on all of this, smallholder farmers' social and cultural identity is an important and essential factor in developing the value chain for dairy production and supporting the rural community, which helps raise the local economy.

According to the United Nations' Women Oxfam report, the roles of men and women in agriculture and livestock are justified based on various factors, the most important of which are the differences in physical strength between them and gender stereotypes [64,65].

Women and men's roles are determined according to the available activities, as men believe that all work and activities that require physical strength are their responsibility. On the other hand, raising livestock and milking cows also requires a massive effort, especially in transporting milk and water intended for washing cows' udders, which is what women do in rural areas [64,65]. However, this patriarchal system is still prevalent in Georgia, especially in rural areas, as this society's traditions place women as responsible people [65-67]. According to the FAO report, many smallholder farmers consider gender equality in Georgia to jeopardise Georgian traditions, identity, and culture, pushing them to adhere to these traditions more strongly [68]. The Georgian government is striving to integrate women into the decision-making process and trying to help them reach the latest developments in the field of livestock breeding $[64,68,69]$.

Thus, a proper understanding of women's role in the dairy chain helps develop and strengthen the dairy value chain. Rural women are the cornerstone for that, starting from the milking stage to preparing raw milk or making cheese for sale. Therefore, these laws and legislation should give more attention to rural women's roles and provide them with all the necessary support to include them in the stage of developing the local economy. 


\subsubsection{Ethical Factors}

Furthermore, animal welfare and the microbiological quality of dairy products are essential factors in livestock breeding. They are closely related to the development of the dairy value chain on the one hand and the maintenance of food safety standards on the other hand.

In addition, microbiological quality is a significant component of the marketing and quality of dairy products, and therefore it is imperative to take this factor into account.

The results of the questionnaire (Figure 6) show that $41.4 \%$ of small farmers put cows in a small closed barn with other animals. This means the animal does not have freedom of movement at all. The area allocated to each animal is minimal, as cleaning, milking, and animal hygiene care is done in an unhealthy manner, and sanitation is almost non-existent. Sometimes the barn is not equipped with windows. The results also show that $41.4 \%$ of farmers keep their animals in a small open barn with other animals, as these animals suffer from the same conditions that the rest of the animals suffer in closed barns, but these barns have access to fresh air. As for $17.1 \%$, they house cows separate from the other farm animals (Table 3), but it also does not fulfil the necessary animal welfare or food safety conditions.

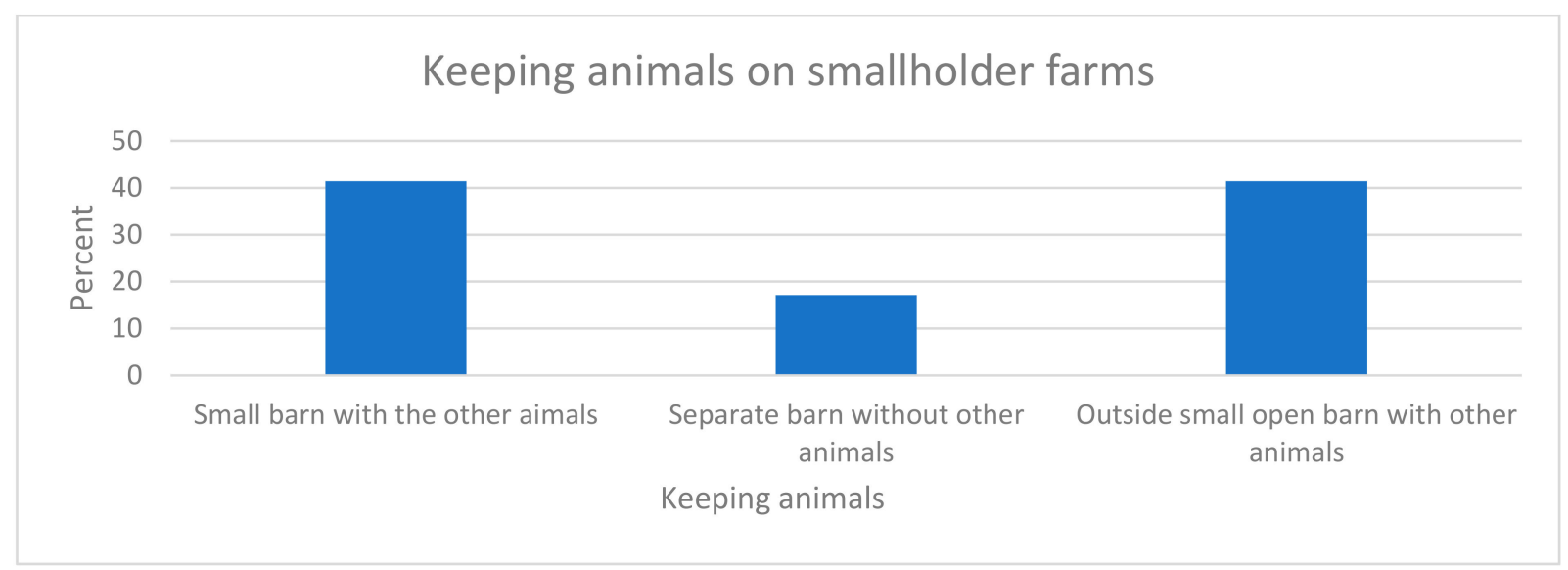

Figure 6. Percentage of farmers keeping cows together with other farm animals or in separate barns in Georgia ( $\mathrm{N}=140$, Mean $=47$, Std. Dev. $=19,629)$.

Table 3. The percentage of farmers interviewed who own other animals on the farm (\%).

\begin{tabular}{cccccc}
\hline $\begin{array}{c}\text { Other Farm Animals Owned by } \\
\text { Farmers }\end{array}$ & Hen & Sheep & Goat & Calf & Pigs \\
\hline $\mathrm{N}^{*}=100 \%$ & 65 & 10 & 5 & 17.1 & 20 \\
\hline${ }^{*} \mathrm{~N}=140$ interviewees. & & & & &
\end{tabular}

By comparing these results with other studies, Gieseke et al. [70] emphasised in a study conducted in Germany the importance of animal welfare in the development of the dairy sector as the cubicle's characteristics play a fundamental role in animal health.

Compared to another study conducted in Sweden, which focused on the importance of animal welfare and its positive effect on production quality, securing the necessary fodder for the cows, treating them well, and ensuring sufficient spaces in the barns help in developing the dairy value chain [71].

Another study in Canada showed that a lack of concern for animal welfare could lead to enormous consequences that harm cows' health and negatively affect the chain [72].

The results of the questionnaire also showed that all farmers interviewed depend only on the hand-milking process. As shown in Table 3, more than half of the farmers, $57.1 \%$, have from one to three cows. Only 5 per cent of them have more than 15 cows. Therefore, a milking machine cannot be considered, as it costs money that the farmer cannot afford. It needs training to use it; also, the farmer does not receive any support from any party. 
However, hand-milking in rural areas is also a big problem, as the questionnaire showed that $85.7 \%$ of farmers (Table 3 ) wash the cow's udder before milking. During the farmers' interview, we asked them to do the cows' milking in front of us if possible, and the results were shocking. Most farmers did not wash their hands before starting the milking process, and some of them had some wounds on their hands that were not covered during the milking process.

On the other hand, most of the places where cows were milked had deplorable sanitary conditions.

Each farmer had specific standards for cleaning the cow's udder. Therefore, fresh milk has not yet been analysed to ensure it is free from any type of bacteria or heavy metals. It is also susceptible to contamination from external factors that are not related to the cow's feed, the type of water supplied, or its health condition. As mentioned earlier, in a subsequent study, the milk taken from the cows of the farmers we interviewed will be analysed to support or reject our hypothesis regarding food safety and smallholder's dairy production.

One of the smallholder farmers stated:

I: "We milk the cows as our parents and grandparents used to do, and their health was durable, and here we are also healthy too, and this is evidence that these methods are feasible." (10 June 2019, Vanati).

Another farmer said:

I: "When we were children, my grandmother would allow us to drink milk directly from the cow's udder without even washing it. That is why our generation is healthier than today's generation. My granddaughter sometimes does not drink milk if it is not boiled." (11 June 2019, Ratevani).

The results show that depending on the Pearson factor in the correlation analysis, there is a strong relationship between the number of cows the farmer owns and between his/her consumption and the milk intended for sale.

A previous study with experts in dairy products [28] showed that it is challenging to monitor farmers fully, as the farmer who sells milk to a third party or dairy and cheese production companies is well observed. Still, the farmers who sell milk on the roads and in the Bazar or small supermarkets find it challenging to monitor them.

According to the FAO reports, small farmers who live in rural areas in Georgia do not have the knowledge and technical expertise to produce safe and high-quality milk. For them, there is no relationship between food safety and human health on the one hand and caring for animal health on the other hand [73,74].

The National Food Agency and the Ministry of Environmental Protection and Agriculture in Georgia are working hard in providing awareness campaigns and training courses in aspects related to livestock breeding. Still, the difficulty of trusting farmers in these departments and organisations is one of the most critical obstacles they face [33]. A smallholder farmer in rural areas trusts other experienced farmers more than they trust these organisations [33]. Likewise, most farmers in rural regions of Georgia are still milking cows by hand. They do not use any equipment for milking, as production on these farms is still rudimentary. Safety requirements and hygiene standards are still not met $[33,73]$.

Despite all the National Food Agency (NFA) efforts and other organisations, farmers in rural areas still make cheese at home without supervision and sell it informally. Hence, food safety and hygiene standards are deficient $[3,26,33,75]$.

At the beginning of 2020, a law was implemented that does not allow homemade cheese to be sold and can be consumed only at home. However, monitoring farmers, informal sales centres, storage, and transportation operations is challenging, negatively affecting dairy's value chain in Georgia and its development $[3,33,75,76]$.

Thus, this research may clarify the importance of balancing the laws stipulated for livestock breeding and animal welfare and farmers' interests (applied or under implementation). For example, these new laws prohibit milk products' direct sale from farmers who did not follow the basic food safety measures. In that case, this may help the local economy 
increase the production of high-efficiency milk from large stables or enterprises. Still, it will negatively affect small farmers because they depend on their daily income by selling raw milk. Therefore, the development plan must provide alternatives to help these farmers with their income or develop their methods used in producing milk.

\subsubsection{Economic Factor}

The questionnaire results also showed that most farmers, at a rate of $53.6 \%$ (Table 2), have significant problems selling the milk they produce, as farmers do not control the dairy market. Therefore, they always resort to selling their products through illegal channels. Previously, farmers relied on an intermediary person who collected milk from farmers and distributed it to dairy and cheese companies. Due to farmers' problems in rural areas and the lack of necessary resources and equipment, the produced milk became incompatible with milk producers' standards. Therefore, as Figure 7 shows, most of the farmers, $42.1 \%$, sell their milk products in the bazaar, $30 \%$ of them depend on small supermarkets, and $17.1 \%$ try to sell what they produce on the roads. As for $20 \%$, they still depend on a third party (collection point).

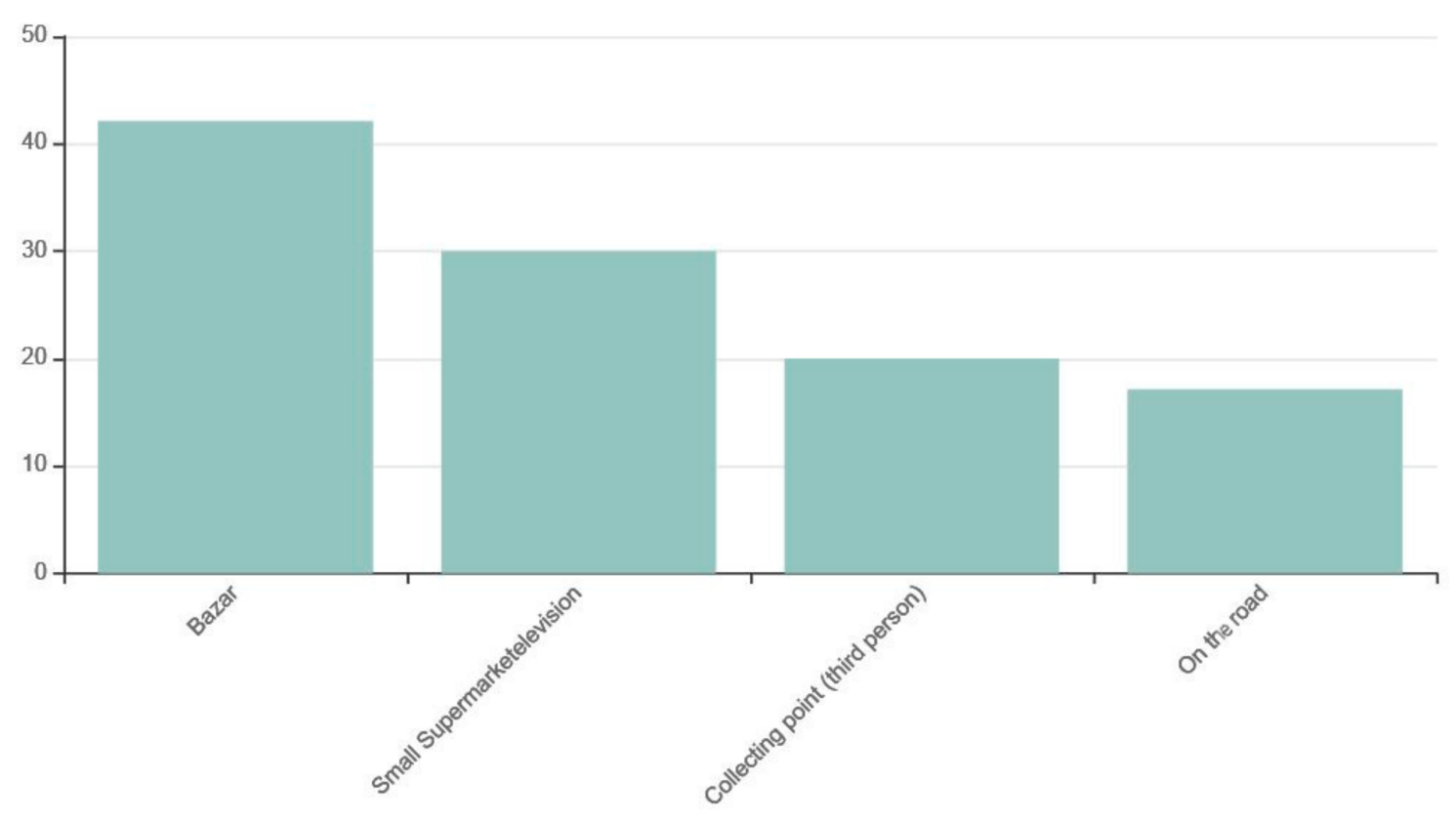

Milk selling point

Figure 7. Milk selling points of smallholder farmers in the Kvemo Kartli region $(\mathrm{N}=140$, Mean = 38, Std. Dev. $=15,840)$.

Farmers cannot produce high-quality milk as they do not have adequate and appropriate resources to reach these standards. Dairy SME and large cheese factories refuse to buy raw milk as it does not follow food safety laws.

To verify the significant issues in terms of selling milk, a T-test was used to compare farmers who suffer from difficulties in selling their milk products and others who do not face this problem (see Table 4). The T-test showed that there is a difference between farmers who suffer from selling the milk compared to others who do not face this problem concerning the amount of fodder in the high season (HS), $\left(\mathrm{Mean}_{\text {with difficulties }}=1.243\right.$, Mean without difficulties $=1.415, \mathrm{t}=-2.051, p<0.05)$. The lack of necessary fodder and pastures negatively affects the quality and quantity of milk, making it difficult to sell, whereas Cohen's $d=-0.349$ suggests a medium effect size of the relevant test. 
Table 4. Independent Samples $t$-Test of the difficulties in selling milk.

\begin{tabular}{|c|c|c|c|c|c|c|c|}
\hline \multicolumn{8}{|c|}{ Independent Samples $t$-Test } \\
\hline \multicolumn{8}{|c|}{ 95\% CI for Mean Difference } \\
\hline & $t$ & df & $p$ & $\begin{array}{c}\text { Mean } \\
\text { Difference }\end{array}$ & Lower & Upper & Cohen's d \\
\hline Keeping animals & 1.114 & 138 & 0.267 & 0.172 & -0.134 & 0.478 & 0.189 \\
\hline reason for starting dairy farming & 3.576 & 138 & $<0.001$ & 0.413 & 0.185 & 0.642 & 0.606 \\
\hline Feeding in HS* & -2.051 & 137 & 0.042 & -0.172 & -0.338 & -0.006 & -0.349 \\
\hline Feeding in LS** & -0.831 & 138 & 0.408 & -0.037 & -0.125 & 0.051 & -0.141 \\
\hline Purchase HS* & -1.729 & 138 & 0.086 & -0.242 & -0.519 & 0.035 & -0.293 \\
\hline Purchase LS** & -1.797 & 138 & 0.075 & -0.155 & -0.325 & 0.016 & -0.304 \\
\hline $\begin{array}{l}\text { Sources of water are available } \\
\text { for animals }\end{array}$ & -2.004 & 138 & 0.047 & -0.149 & -0.295 & -0.002 & -0.340 \\
\hline Average of the milk in $\mathrm{HS}{ }^{*} \mathrm{~L} /$ day & 0.105 & 138 & 0.917 & 0.013 & -0.238 & 0.265 & 0.018 \\
\hline Average of the milk in LS $* * \mathrm{~L} /$ day & 0.542 & 138 & 0.589 & 0.042 & -0.111 & 0.195 & 0.092 \\
\hline Cheese varieties & 0.067 & 138 & 0.946 & 0.008 & -0.233 & 0.249 & 0.011 \\
\hline
\end{tabular}

Note. Student's $t$-test, ${ }^{*}$ HS: high season: from March to August, ${ }^{* *}$ LS: low season: from September to February.

This difference also appears regarding the animals' water sources (Mean ${ }_{\text {with difficulties }}$ $=1.667$, Mean without difficulties $=1.815, \mathrm{t}=-2,004, p<0.05)$. As in the scarce seasons, it is challenging to sell milk, but also, with the lack of water, selling becomes more difficult for these farmers. Cohen's $d=-0.340$ suggests a medium effect size of the relevant test. Therefore, farmers are still suffering from a large problem in selling their milk products, and the gap between them and the small and large milk producers have become very complicated.

Spearman correlation analysis was applied to analyse the data. Table 5 shows that the correlation between the purchase in the low season and the average of the milk in the low season is $r_{s}=0.304(p<0.001)$; thus, the correlation is statistically significant. The positive sign of the correlation coefficient shows that this is a relationship between the two variables in the same way; this means that higher purchase values in the low season are associated with higher milk values in the low season. Likewise, Table 4 shows that the correlation between the purchase in the high season and the average of the milk in the high season is $r_{s}=0.395(p<0.001)$; thus, the correlation is statistically significant. The positive sign of the correlation coefficient shows that this is a relationship between the two variables, which means that higher purchase values in the high season are associated with higher milk values in the high season.

Table 5. Correlation matrix of milk production and animal feeding (Spearman correlations-rs).

\begin{tabular}{|c|c|c|c|c|c|c|c|c|c|c|c|c|}
\hline \multicolumn{13}{|c|}{ Spearman's Correlations } \\
\hline \multicolumn{2}{|l|}{ Variable } & \multicolumn{2}{|c|}{$\begin{array}{l}\text { Feeding in } \\
\text { HS. }\end{array}$} & \multicolumn{2}{|c|}{ Purchase HS. } & \multicolumn{2}{|c|}{ Purchase LS. } & \multicolumn{2}{|c|}{$\begin{array}{l}\text { Feeding Grass in the } \\
\text { Mountain in HS. }\end{array}$} & \multicolumn{2}{|c|}{$\begin{array}{l}\text { Average of the } \\
\text { Milk in H.S. } \\
\text { L/Day }\end{array}$} & \multirow[t]{2}{*}{$\begin{array}{l}\text { Average of } \\
\text { the Milk in } \\
\text { L.S. L/Day }\end{array}$} \\
\hline Feeding in HS. & Spearman's rho & - & & & & & & & & & & \\
\hline Purchase HS. & Spearman's rho & 0.257 & $* *$ & - & & & & & & & & \\
\hline Purchase LS. & Spearman's rho & 0.208 & $*$ & 0.794 & $* * *$ & - & & & & & & \\
\hline $\begin{array}{l}\text { Feeding Grass in the } \\
\text { mountain in HS. }\end{array}$ & Spearman's rho & 0.149 & & -0.135 & & 0.006 & & - & & & & \\
\hline $\begin{array}{c}\text { Average of the milk in } \\
\text { H.S. L/day }\end{array}$ & Spearman's rho & 0.386 & $* * *$ & 0.395 & $* * *$ & 0.333 & $* * *$ & -0.127 & - & & & \\
\hline $\begin{array}{l}\text { Average of the milk in } \\
\text { L.S. L/day }\end{array}$ & Spearman's rho & 0.301 & $* * *$ & 0.372 & $* * *$ & 0.304 & $* * *$ & -0.048 & 0.589 & $* * *$ & - & \\
\hline
\end{tabular}

${ }^{*} p<0.05,{ }^{* *} p<0.01,{ }^{* * *} p<0.001$, H.S.: high season, LS: low season.

Comparing these results with the previous ones of expert interviews [28] showed that government agencies specialising in the field of dairy and cheese production and small and large factories require farmers to obtain milk of high standards, which includes all the conditions and specifications of food safety. Smallholder farmers, in turn, do not 
have sufficient and necessary resources to fulfil these conditions, so a large gap has arisen between these parties.

Experts have confirmed that smallholder farmers play an essential role in the new laws and legislation in dairy production. Compared to this questionnaire's results, farmers suffer from many problems, and government support for them is insufficient, as the relationship is poor between them. One of the farmers interviewed stated when we asked him if he suffers from a lack of feed or water:

I: "Veterinarians are the only ones who communicate with us, but also not always. In specific periods of the season, we may suffer from a shortage of feed or even water, and we do not always have the price of preserved fodder. At that time, the cows may suffer from some diseases, and their production will be deficient, so then we find only these veterinarians to help us." (9 June 2019, Bolnisi).

Another farmer stated:

I: "When we see one of the government agencies in our village, we know immediately that problems are coming, so it is better to avoid talking to them." (12 June 2019, Mtskneti).

Moreover, this study shows that smallholder farmers face different problems in the Georgian dairy value chain than those faced by experts and government agencies. The experts focused on food safety and international food safety standards and their importance in developing the value chain for dairy production. In contrast, the farmer sees this problem differently; for example, water availability and quality are some of the most critical factors for small farmers. As Table 2 shows, $81.4 \%$ of farmers do not have enough water for their livestock, and all of them depend on the existing rivers.

As indicated by the survey, in the Kvemo Kartli region, farmers depend mainly on the Khrami River and the Mashavera river. Table 6 shows the value of the Chi-Square test $\left(\mathrm{X}^{2}=3.961, \mathrm{df}=1, p<0.05\right)$, as it explains that the farmers who are dependent on these two rivers have problems selling their milk. These results suggest that the respondents in the Khrami River area face more problems by selling their milk than in the area of the Mashavera River.

Table 6. Chi-Square Test of the difficulties selling milk.

\begin{tabular}{|c|c|c|c|c|c|}
\hline \multicolumn{6}{|c|}{ Contingency Tables } \\
\hline \multirow[b]{2}{*}{$\begin{array}{l}\text { Sources of Water Are } \\
\text { Available for Animals }\end{array}$} & \multicolumn{5}{|c|}{ Difficulties Selling Milk } \\
\hline & Yes & No & & Total & \\
\hline Khrami River & 25 & 12 & & 37 & \\
\hline Mashavera River & 50 & 53 & & 103 & \\
\hline Total & 75 & 65 & & 140 & \\
\hline & \multicolumn{2}{|c|}{ Chi-Squared Tests } & & & \\
\hline & Value & df & $p$ & & \\
\hline$x^{2}$ & 3.961 & 1 & 0.047 & & \\
\hline Likelihood ratio & 4.039 & 1 & 0.044 & & \\
\hline $\mathrm{N}$ & 140 & & & & \\
\hline & \multicolumn{2}{|c|}{ Log Odds Ratio } & & & \\
\hline & \multicolumn{5}{|c|}{ 95\% Confidence Intervals } \\
\hline & Log Odds Ratio & Lower & Upper & & $p$ \\
\hline Odds ratio & 0.792 & 0.003 & 1.582 & & \\
\hline Fisher's exact test & 0.787 & 0.063 & $\infty$ & & 0.035 \\
\hline
\end{tabular}

Note. For all tests, the alternative hypothesis specifies that group Khrami River is more significant than Mashavera River. 
A farmer declared the following when asked whether the current water source suffices his needs for the whole year:

I: "The river is not close to my house, and therefore we have to walk a long distance every day to bring water for the livestock, as drinking water is limited, and we cannot always give our livestock from it. Unfortunately, no one offers us an alternative or solution to this problem." (9 June 2019, Chapala).

And another stated:

I: "How can the milk production of my cows be high when we do not have enough water or sufficient amount of feed?" (13 June 2019, Kvemo Bolnisi).

A T-test was used to compare farmers' difficulties, depending on the two rivers that pass through these villages (see Table 7), because the hypothesis states that people in this region of Khrami River have different answers from farmers in the region of Mashavera river.

Table 7. Independent Samples $t$-Test of the available water sources.

\begin{tabular}{|c|c|c|c|c|c|c|c|}
\hline \multicolumn{8}{|c|}{ Independent Samples $t$-Test } \\
\hline & \multirow[b]{2}{*}{$\mathbf{t}$} & \multirow[b]{2}{*}{ df } & \multirow[b]{2}{*}{$p$} & \multicolumn{4}{|c|}{ 95\% CI for Mean Difference } \\
\hline & & & & $\begin{array}{c}\text { Mean } \\
\text { Difference }\end{array}$ & Lower & Upper & Cohen's d \\
\hline Keeping animals & -1.262 & 138 & 0.209 & -0.220 & -0.566 & 0.125 & -0.242 \\
\hline $\begin{array}{l}\text { reason for starting dairy } \\
\text { farming }\end{array}$ & 2.590 & 138 & 0.011 & 0.346 & 0.082 & 0.609 & 0.496 \\
\hline Feeding in H.S * & 0.520 & 137 & 0.604 & 0.050 & -0.141 & 0.242 & 0.101 \\
\hline Feeding in L.S ** & -0.083 & 138 & 0.934 & -0.004 & -0.104 & 0.095 & -0.016 \\
\hline Purchase H.S * & 1.300 & 138 & 0.196 & 0.207 & -0.108 & 0.521 & 0.249 \\
\hline Purchase L.S ** & 1.652 & 138 & 0.101 & 0.161 & -0.032 & 0.354 & 0.317 \\
\hline $\begin{array}{c}\text { Average of the milk in } \\
\text { H.S }{ }^{*} \text { L/day }\end{array}$ & 0.546 & 138 & 0.586 & 0.078 & -0.206 & 0.363 & 0.105 \\
\hline $\begin{array}{l}\text { Average of the milk in } \\
\text { L.S }{ }^{* *} \mathrm{~L} / \text { day }\end{array}$ & 2.273 & 138 & 0.025 & 0.196 & 0.025 & 0.367 & 0.436 \\
\hline Difficulties selling milk & -2.004 & 138 & 0.047 & -0.190 & -0.378 & -0.003 & -0.384 \\
\hline Cheese varieties & -0.716 & 138 & 0.475 & -0.099 & -0.371 & 0.174 & -0.137 \\
\hline
\end{tabular}

${ }^{*}$ HS: high season, ${ }^{* *}$ LS: low season.

The test showed a fundamental difference in milk production between farmers who use the Khrami River compared with farmers from other villages who depend on the Mashavera River in LS.

The milk production of farmers in the Khrami River region is, on average, higher than the milk production of the farmers in the Mashavera River region (Mean Khrami $=1.351$, Mean $_{\text {Mashavera }}=1.155, \mathrm{t}=2.273, p<0.05$ ). Simultaneously, the farmers in the Mashavera River region suffer from many problems, including the difficulty of accessing river water or permanent water pollution. Cohen's $d$ value (Cohen's $d=-0.340)$ suggests a medium effect size of the relevant test.

Nevertheless, as shown in Table 2, $96.4 \%$ of the farmers do not have sufficient fodder for cows for the whole year, and they cannot make preserved fodder (such as hay; see Figure 4). Therefore, the cows suffer from a significant shortage of feed, which is negatively reflected in the amount of milk production.

A T-test was used to compare farmers who have enough fodder for their animals (for the entire year) and others who do not (see Table 8). It is essential to know if the farmers depend only on local pastures or different types of local or imported feed. The T-test showed that there is a difference between farmers who have enough fodder compared to others who do not have the required amount of fodder in the low season (LS), (Mean have enough fodder $=1.400$, Mean $_{\text {don't have enough fodder }}=1.044, t=-3.069, p<0.05$ ). 
Table 8. Independent Samples $t$-Test of Enough Fodder for dairy animals (for the entire year).

\begin{tabular}{|c|c|c|c|}
\hline \multicolumn{4}{|c|}{ Independent Samples $t$-Test } \\
\hline & $\mathbf{t}$ & df & $p$ \\
\hline Size of the household & 0.706 & 138 & 0.481 \\
\hline Number of cows & -0.160 & 138 & 0.873 \\
\hline Milking the cows (per day) & 2.304 & 138 & 0.023 \\
\hline Milk for cheese production & 0.562 & 138 & 0.575 \\
\hline Feeding in L.S ** & 3.069 & 138 & 0.003 \\
\hline Purchase H.S * & 0.312 & 138 & 0.756 \\
\hline Purchase LS ** & $\mathrm{NaN}$ & & \\
\hline Feeding in H.S * & 2.201 & 137 & 0.029 \\
\hline Starting dairy farm & $\mathrm{NaN}$ & & \\
\hline Processing cheese & -0.896 & 138 & 0.372 \\
\hline $\begin{array}{l}\text { Responsibility for feeding, cleaning, milking, } \\
\text { and processing as well as marketing }\end{array}$ & 0.219 & 138 & 0.827 \\
\hline Average of the milk in HS * L/day & 1.198 & 138 & 0.233 \\
\hline Average of the milk in LS ${ }^{* *} \mathrm{~L} /$ day & -0.035 & 138 & 0.972 \\
\hline Milk consumption at home & -0.669 & 138 & 0.505 \\
\hline Milk sold & -0.335 & 138 & 0.738 \\
\hline
\end{tabular}

Note. Student's $t$-test, ${ }^{*}$ HS: high season, ${ }^{* *}$ LS: low season

Studies have shown that the Georgian agencies in the development of the dairy sector in Georgia are working to legislate and apply strict laws and regulations, which raise the efficiency and quality of the final product [27].

However, after the Georgian government adopted a unique system concerned with food safety in the country in 2010 [77], several new laws and legislation entered into force in 2020. These laws prevented all dairy companies from purchasing and collecting milk from farmers whose cows were not registered in the official government system [26]. Moreover, in 2014, after the signing of the joint agreement "EU-Georgia Association Agreement" between Georgia and the European Union, Georgia is working hard to implement all food safety standards applied in the European countries [78,79].

However, all of these laws serve the consumer, and for the producer's interest so as to produce sufficient quantities of high-quality milk, adequate amounts of good quality feed must be available. Therefore, farmers try to save some money to buy preserved or concentrated fodder, especially for winter (wheat, corn, and straw). Thus, it becomes difficult for them to secure cleaning and sanitation services for their barns [53].

The Georgian government provides veterinary services for free. However, farmers sometimes need to pay specific amounts to obtain certain medicines for their cows because these services do not always include giving medicines free of charge. Therefore, they treat their cows with antibiotics, which pose a significant danger to human health and the quality and safety of the milk produced [79].

Compared to other studies, Belay et al. [80] showed the importance and influence of the socio-economic characteristics of dairy farmers on the management and development of the dairy sector, which demonstrated the strong correlation between the education level and years of experience with dairy management practices. Tina et al. [2] also confirmed that taking into account the social and economic factors in the dairy sector significantly affects its sustainability and the development of the dairy value chain, especially if the other factors that affect the chain are taken into consideration. In addition, as Mlelwa emphasised in his research, the dairy sector is significantly influenced by several socio-economic factors, such as the number of cows, the farmer's experience, knowledge, and workforce in each household, which all play an essential role in the development of this chain [81].

The Georgian government has come a long way in developing a sustainable food safety system in the country. The National Food Agency (NFA) built significant relationships with smallholder farmers, especially in rural areas. Where the NFA is the leading player in the Georgian agricultural sector, it is directly responsible for consumer protection, applying 
food safety standards in the country, examining all dairy products' components, and comparing them to the final product [76,82]. Besides, Georgia now has a database to register animals electronically to monitor all dairy and cheese production activities and directly intervene if necessary [26].

Thus, based on all of the information mentioned in this section, the results of this research may help identify points of difference between decision-makers in governmental institutions and dairy experts on the one hand and smallholder farmers on the other hand. The comparison that was made between these parties and clarifying the problems these people face may offer future solutions based on the main factors mentioned in this research, which may be in the interest of all parties.

\section{Conclusions}

Smallholder farmers were and still are the cornerstone of the agricultural and dairy sector in Georgia. This study presents interviews with smallholder farmers in the leading region for milk and cheese production in Georgia. The results show their point of view, fear, wishes, and challenges and may help reach a common solution on how the dairy value chain should be developed. It may help government agencies to implement their plans for developing the dairy sector in Georgia and, at the same time, reach high food safety standards. The analyses of milk and cheese samples being purchased from the interviewed farmers will be analysed and may show critical points in the dairy value chain.

This study showed the impact of smallholder farmers' ethical and cultural identity on the Georgian dairy value chain. Farmers still adhere to the ancient traditions they inherited from their parents and grandparents, and rural women are still under the influence of those traditions. Although in this pastoral society, women are considered the primary and active element in the process of dairy production and cheese making, women do not have access to modern technology and studies related to dairy production. As a previous study with some experts in dairy production in Georgia showed, women are not concerned with much interest in development and modernisation programs for the dairy production sector in Georgia. This proves that smallholder farmers' ethical and cultural identity is a fundamental factor in developing the value chain of Georgian domestic dairy products.

The questionnaire results indicated that farmers are afraid of increasing the number of large dairy producers in Georgia, as smallholder farmers' production capacity is limited. Smallholder farmers cannot meet the substantial market requirements, and it is difficult to adhere to the stipulated food safety conditions. Thus, this confirms that farmers fear that their presence in the dairy market will be threatened by specialised farms that produce large quantities of raw milk.

However, smallholder farmers' microbiological quality of their dairy products is no longer acceptable in the market. As a result, farmers suffer from the constant fear of not selling their raw milk and homemade cheese products.

The study also showed that the problems that farmers suffer from are entirely different from those problems that the experts stressed in a previous study that farmers suffer from.

As the questionnaire results showed, the lack of fodder and water scarcity and its low quality are fundamental problems that farmers face. The government is working to secure enough pastures for farmers in the summer, but that is not enough, as farmers do not have enough fodder or money to buy what is necessary for the winter season. The problems of river cleanliness in villages and river pollution with heavy metals do not receive much attention from the government agencies concerned. Therefore, directly and indirectly, all of this affects the quality of milk and cheese made in rural areas.

From the point of view of dairy experts, the problems of hygiene and animal welfare on the one hand, and the marketing of raw milk and dairy products, on the other hand, are the significant challenges facing these farmers. Thus, this proves a gap between dairy farmers and governmental and private organisations prioritising smallholder farmers' problems. On the other hand, these farmers do not give the quality of milk and animal welfare great importance due to the economic conditions and the problems they suffer from. 
Hence, this study's results may help develop the dairy value chain in Georgia, where all the factors and components of this chain must be taken into account. The work of all actors and the continuous coordination between them will ensure the sustainability of this value chain.

On the other hand, the question remains open. Assuming that this stipulated legislation and laws have worked in smallholder farmers' interest and considered the factors critical to them, will this only have a positive impact? For years, these traditions used by smallholder farmers have been an essential part of the dairy sector's development stage in Georgia. Besides, will these farmers have the ability to control the local market or even develop production to suit food safety requirements if they can export their products to other countries?

The inability of smallholder farmers to cope with the changes taking place in the dairy sector may lead to the abandonment of farms, which in turn leads to a change in the range of products, a change in the cultural landscape (although there are under industrial animal husbandry, but more cows are kept in the barn), and food security changes. Therefore, the government should support the preservation of smallholder farmers through training and subsidies to create healthy and social living conditions.

Food safety laws have not curbed the pollution of rivers, soils, and plants with heavy metals from another perspective. The safety of farmers and the preservation of local production of high-quality milk and cheese should take priority.

Author Contributions: R.A.S., T.U., and A.P. conceived and designed the experiments; R.A.S. wrote the manuscript of the publication, A.P. supervised the working process. All authors have read and agreed to the published version of the manuscript.

Funding: This research study is a part of the cooperative research work between the University of Kassel, Faculty for Organic Agricultural Sciences, and the Agricultural University of Georgia, since 2018. The VW Foundation and Shota Rustaveli National Science Foundation finances the research project "Structured PhD- Program on Sustainable Agricultural and Food Systems" (SAFS), of which this empirical study was part of.

Institutional Review Board Statement: Not applicable.

Informed Consent Statement: Not applicable.

Data Availability Statement: Not applicable.

Conflicts of Interest: The authors declare no conflict of interest.

\section{Appendix A}

Table A1. Questionnaire Data.

\begin{tabular}{cc}
\hline Domains and Variables & Questions \\
\hline & Upstream (Input Supplies) \\
\hline Socio-Demographic/Socio-Geographic \\
\hline Village \\
\hline Gender \\
\hline Household socio-economic background \\
\hline Size of the household \\
\hline Keeping animals \\
\hline $\begin{array}{c}\text { Dairy production or animal husbandry is the only } \\
\text { financial income }\end{array}$
\end{tabular}


Table A1. Cont.

\begin{tabular}{|c|c|}
\hline Domains and Variables & Questions \\
\hline \multicolumn{2}{|c|}{ On-farm (production) } \\
\hline \multicolumn{2}{|c|}{ General } \\
\hline Starting dairy farm & When did you start dairy farming? \\
\hline Basic knowledge of dairy farming & Did you have basic knowledge of dairy farming? \\
\hline Reasons for starting dairy farming & For which reason did you start dairy farming? \\
\hline \multicolumn{2}{|c|}{ Dairy farm structure, facilities and management } \\
\hline Other livestock on the farm & Do you have any other livestock on your farm? \\
\hline Number of cows & How many dairy cattle do you have on your farm? \\
\hline Responsibility on the animals/farm & Who is responsible for the animals on the farm? \\
\hline Animal breed & Which animal breed you have? \\
\hline Cows for milk and meat purposes & Are your cows for milk or meat purposes? \\
\hline
\end{tabular}

\section{Labour use in dairy farming}

\section{Responsibility for feeding, cleaning, milking, and processing as How many persons are responsible for feeding cleaning milking} well as marketing and processing as well as marketing?

\section{Feeding}

Type of grazing for dairy animals

Can you tell me which type of grazing do you practise for your dairy animals and how many months a year?

\begin{tabular}{cc}
\hline & Feeding type \\
\hline Type of fertiliser on your grazing land & Are you using any type of fertiliser on your grazing land? \\
\hline Sending the cows to the mountain in HS. \\
\hline Feeding in the high season (HS.) \\
\hline Feeding in the low season (LS.) \\
\hline Purchase in the high season (HS.) \\
\hline Purchase in the low season (LS.)
\end{tabular}

Enough fodder for dairy animals (for the entire year)

Making conserved feed (e.g., hay)

Sources of water are available for animals

Satisfied with the water quality of the primary water sources

Water-amount enough for animals (yearly)
Do you have enough fodder for your dairy animals for the entire year?

Are you used to making conserved feed, e.g., hay?

Which sources of water are available for your animals?

Are you satisfied with the water quality of the primary water sources?

Do you have enough water to feed animals yearly?

\section{Output (Downstream)}

How many times do you milk your cows (per day)?

What is the average of the milk in HS (L/day)?

What is the average of the milk in LS (L/day)?

Would you like to increase your milk production?

Please can you tell me your milk consumption at home (\%)

Milk selling point

Difficulties selling milk
Are there any specific selling points where you are marketing your milk?

Do you ever face any difficulties selling your milk? 
Table A1. Cont.

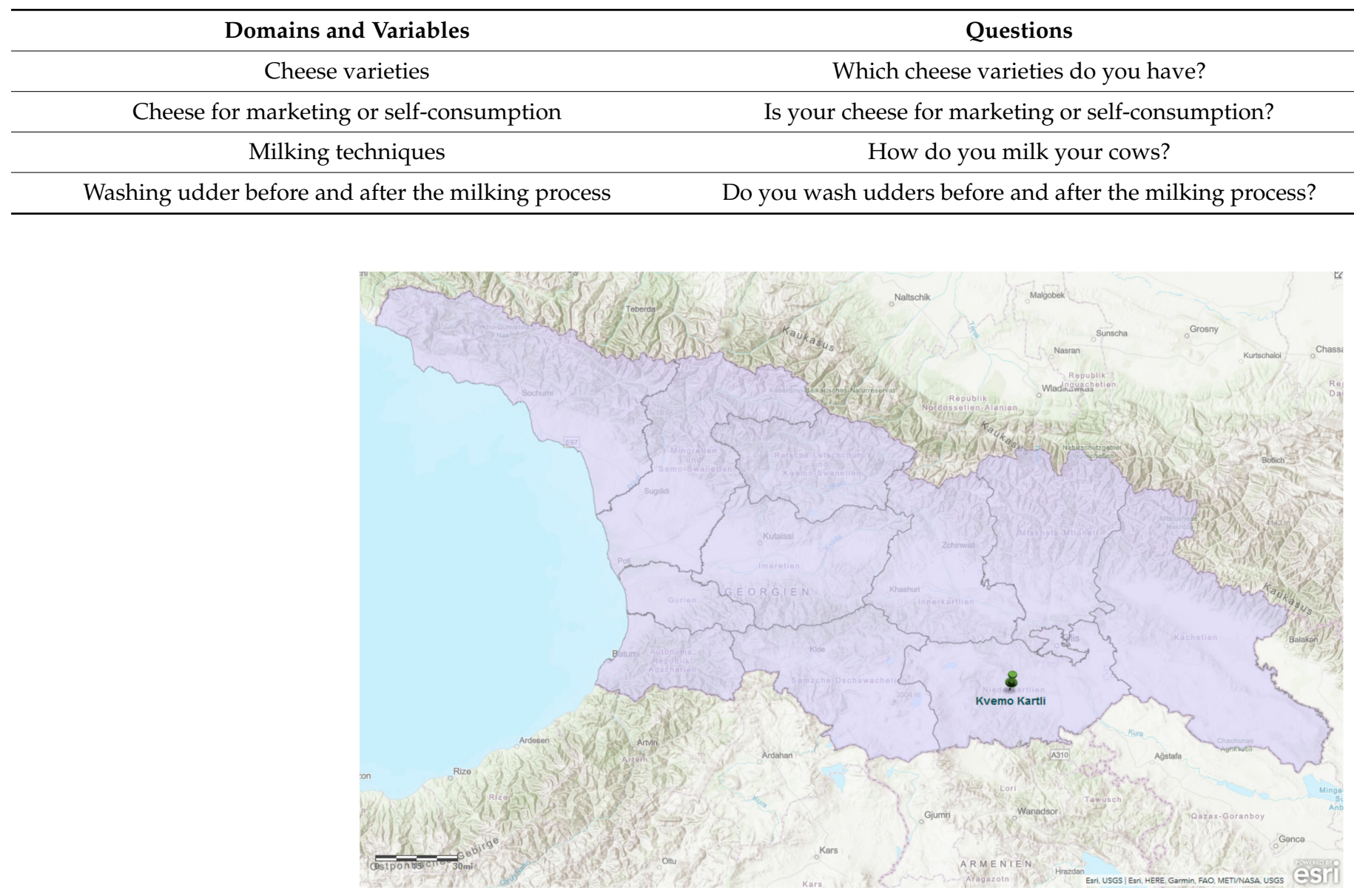

Figure A1. Georgia Map; ArcGIS Pro Data sources: Base map layer; ESRI satellite (ArcMap).

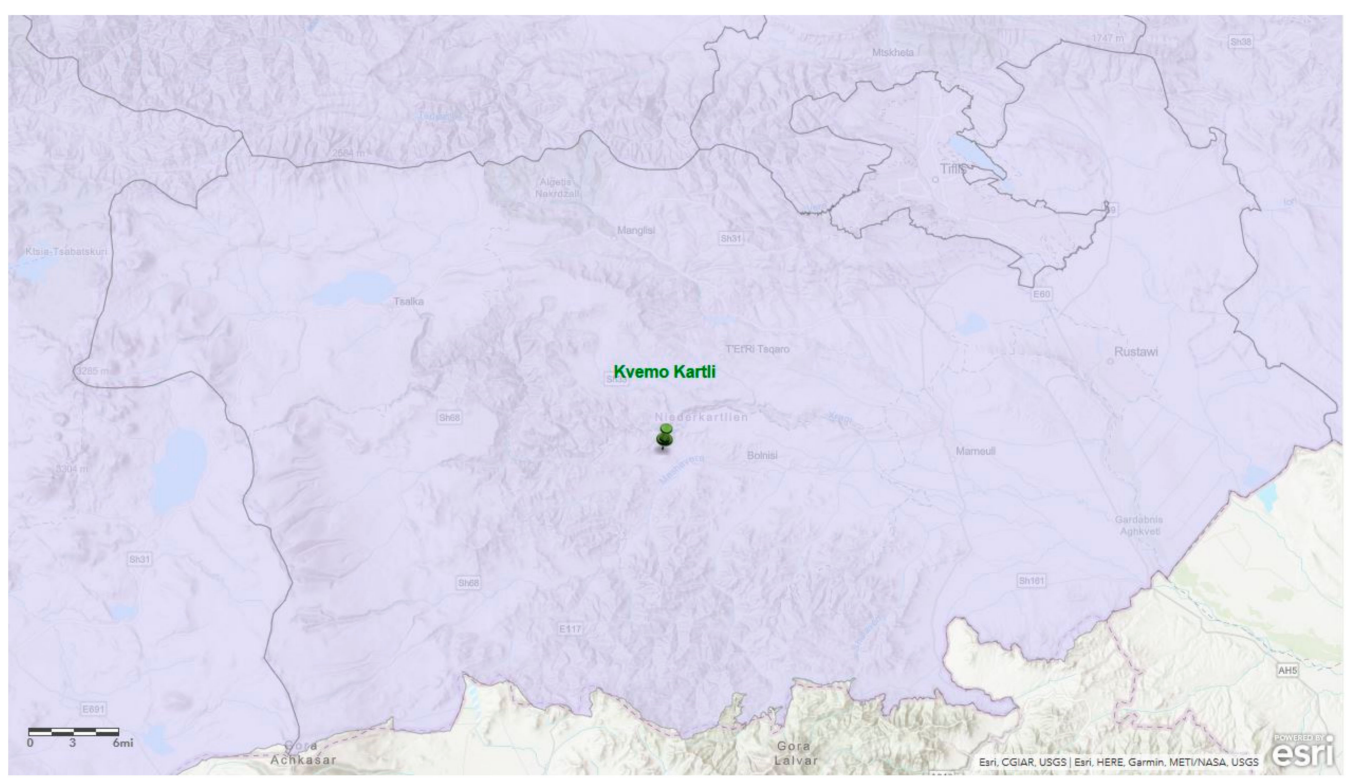

Figure A2. Kvemo Kartli region (Authors' illustration); ArcGIS Pro, Data sources: Base map layer; ESRI satellite (ArcMap). 


\section{References}

1. FAO. Transforming Food and Agriculture to Achieve the SDGs; FAO: Rome, Italy, 2018; ISBN 9789251306260.

2. Jaklič, T.; Juvančič, L.; Kavčič, S.; Debeljak, M. Complementarity of socio-economic and emergy evaluation of agricultural production systems: The case of Slovenian dairy sector. Ecol. Econ. 2014, 107, 469-481. [CrossRef]

3. ALCP. Ensuring Sustainability in the Dairy Market Sector; Swiss Agency for Development and Cooperation (SDC): Bern, Swiss, 2017.

4. Wolfenson, K.D.M. Coping with the Food and Agriculture Challenges: Smallholder Farmers' Agenda; Food and Agriculture Organisation of the United Nations (FAO): Rome, Italy, 2013.

5. Markelova, H.; Meinzen-Dick, R.; Hellin, J.; Dohrn, S. Collective action for smallholder market Access. Food Policy 2009, 34, 1-7. [CrossRef]

6. Hong, D. On World Food Day, Farmers should Come First; One AcreFund Global: Kakamega, Kenya, 2015.

7. Olomola, A. Policy Options for Agricultural Investments and Governance of Markets: In Support of Small-Scale Agriculture in Nigeria; Oxfam Research Report; Oxfam International: Oxford, UK, 2013.

8. FAO. Guide to Good Dairy Farming Practice-Animal Production and Health-Guidelines. No. 8; Food and Agriculture Organisation of the United Nations (FAO): Rome, Italy; International Dairy Federation: Brussels, Belgium, 2011. Available online: http: //www.fao.org/3/ba0027e/ba0027e00.pdf. (accessed on 13 May 2021).

9. Wouters, A.P.; van der Lee, J. Smallholder Dairy Development-Drivers, Trends and Opportunities; WUR: Wageningen, The Netherlands, 2009.

10. FAO. Milk/Dairy Products: Agribusiness Handbook; Food and Agriculture Organisation of the United Nations (FAO): Rome, Italy, 2009.

11. Morgan, N. Smallholder Dairy Development: Lessons Learned in Asia; Animal Production and Health Commotion for Asia and the Pacific: Bangkok, Thailand; FAO: Rome, Italy, 2009.

12. Hemme, T.; Otte, J. Status and Prospects for Smallholder Milk Production: A Global Perspective; Food and Agriculture Organization of the United Nations (FAO): Rome, Italy, 2010.

13. Rangnekar, D.; Thorpe, W.R. Smallholder Dairy Production and Marketing_Opportunities and Constraints; International Livestock Research Institute (ILRI): Nairobi, Kenya, 2001.

14. Thornton, P.K. Livestock production: Recent trends, future prospects. Philos. Trans. R. Soc. B Biol. Sci. 2010, 365, $2853-2867$. [CrossRef] [PubMed]

15. ENPARD. Milk and Dairy Production Agricultural: Agricultural Value Chain in Imereti and Racha Regions; Enhancing Small Farmers' Cooperation and Productivity in Imereti and Racha Regions (ENPARD): Tbilisi, Georgia, 2015; pp. 1-27.

16. CARD. Business Case Study Dairy Sector in Georgia; Center for Agribusiness and Rural Development: Tbilisi, Georgia, 2018.

17. Lerman, Z.; Csaki, C.; Feder, G. Agriculture in Transition: Land Policies and Evolving Farm Structures in Post-Soviet Countries; Lexington Books: Lanham, MD, USA, 2004; ISBN 0739108077.

18. Terra Institute, Ltd. Georgia Land Market Development Project Final Report; Terra Institute, Ltd.: Blue Mounds, WI, USA, 2005. Available online: http://www.terrainstitute.org/pdf/Georgia_LMDP_Final_Report.pdf (accessed on 15 October 2020).

19. SDC. Alliances Kk Synthesis Report of the First Phase: September 2011 to September 2013; Swiss Development Cooperation (SDC): Kvemo Kartli, Georgia, 2013. Available online: http://alcp.ge/pdfs/9b82125e5c11d2996b53c881302f1447.pdf (accessed on 12 October 2020).

20. ISET Policy Institute. Policy Clarification; Agricultural Registration Reform in Georgia: Tbilisi, Georgia, 2018; pp. 1-17. Available online: https:/ /iset-pi.ge/images/Projects_of_APRC/Policy_Paper_Agricultural_Land_Registration_Reform_in_Georgia_ GEO.pdf (accessed on 20 September 2020).

21. EI-LAT. The Economic Transformation of Georgia in Its 20 Years of Independence; Summary of the Discussion Paper; Liberal AcademyTbilisi: Tbilisi, Georgia, 2012.

22. Gvaramia, A. Land Ownership and the Development of the Land Market in Georgia; ALCP Study: Tbilisi, Georgia, 2013.

23. ISET Policy Institute. Safety and Quality Investment in Livestock: Georgian Dairy Market System Analysis and Mapping; ISET Policy Institute: Tbilisi, Georgia, 2019.

24. Damenia, N.; Kharaishvili, E.; Sagareishvili, N.; Saghareishvili, M. Women's Employment Issues in Georgia and Solutions Based on European Experience. Intern. J. Econ. Manag. Eng. 2019, 14, 530-536.

25. UN-Resolution der Generalversammlung, Resolution der Generalversammlung, Verabschiedet am 25. September 2015. 2015. Available online: https:/ / www.un.org/Depts/german/gv-70/band1/ar70001.pdf (accessed on 5 October 2020).

26. Gelashvili, S.; Deisadze, S. Difficulties of Implementing the Technical Regulation on Milk and Dairy Products; ISET Policy Institute: Tbilisi, Georgia, 2019.

27. Raaflaub, M.; Dobry, L.M. Pasture Management in Georgia. Current Situation, Frame Conditions, Potentials of Development; Swiss Agency for Development and Cooperation SDC: Bern, Switzerland, 2015; Volume 42.

28. Al Sidawi, R.; Urushadze, T.; Ploeger, A. Changes in Dairy Products Value Chain in Georgia. Sustainability 2020, $12,5894$. [CrossRef]

29. Withanachchi, S.S.; Kunchulia, I.; Ghambashidze, G.; Al Sidawi, R.; Urushadze, T.; Ploeger, A. Farmers' perception of water quality and risks in the Mashavera River Basin, Georgia: Analysing the vulnerability of the social-ecological system through community perceptions. Sustainability 2018, 10, 3062. [CrossRef] 
30. Boogaard, B.; Oosting, S.; Bock, B. Defining sustainability as a socio-cultural concept: Citizen panels visiting dairy farms in the Netherlands. Livest. Sci. 2008, 117, 24-33. [CrossRef]

31. Galmessa, U.; Dessalegn, J.; Tola, A.; Prasad, S.; Kebede, L.M. Dairy production potential and challenges in western Oromia milk value chain, Oromia, Ethiopia. J. Agric. Sustain. 2013, 2, 1-21.

32. Kartvelishvili, T. Cattle sector and dairy chain developments in Georgia, Azerbaijan and Armenia. In The Cattle Sector in Central and Eastern Europe: Developments and Opportunities in a Time of Transition; Wageningen Academic Publishers: Wageningen, The Netherlands, 2009; p. 133.

33. CARD. Baseline Assessment of the Dairy Sector in Georgia; Center for Agribusiness and Rural Development: Tbilisi, Georgia, 2018.

34. FAO-EBRD. Support to Sustainable Value Chains through the Development of Geographical Indications in the Dairy Sector; European Bank for Reconstruction and Development: London, UK, 2016.

35. CRRC. Dairy and Beef Consumer Preferences; Caucasus Research Resource Center: Tbilisi, Georgia, 2018.

36. ISET-PI. Livestock Farm-Enterprise Models in the Kakheti Region: Current Arrangements and Options for (Re-)Gaining Size and Competitiveness; ISET-PI: Tbilisi, Georgia, 2016.

37. Bickerstaff, K. Risk perception research: Socio-cultural perspectives on the public experience of air pollution. Environ. Int. 2004, 30, 827-840. [CrossRef]

38. Dogaru, D.; Zobrist, J.; Balteanu, D.; Popescu, C.; Sima, M.; Amini, M.; Yang, H. Community Perception of Water Quality in a Mining-Affected Area: A Case Study for the Certej Catchment in the Apuseni Mountains in Romania. Environ. Manag. 2009, 43, 1131-1145. [CrossRef]

39. Slovic, P. Trust, Emotion, Sex, Politics, and Science: Surveying the Risk-Assessment Battlefield. Risk Anal. 1999, 19, 689-701. [CrossRef]

40. Leiserowitz, A. Climate Change Risk Perception and Policy Preferences: The Role of Affect, Imagery, and Values. Clim. Chang. 2006, 77, 45-72. [CrossRef]

41. Eurostat. Global Assessment of the National Statistical System of the Republic of Georgia; Eurostat (The Statistical Office of the European Union): Tbilisi, Georgia, 2019. Available online: https:/ /www.unece.org/fileadmin/DAM/stats/documents/technical_coop/ GA_Georgia_2019_EN.pdf (accessed on 5 October 2020).

42. National Statistics Office of Georgia. Geostat Agriculture of Georgia, Retro-Projection of Main Demographic Indicators for the Period 1994-2014; National Statistics Office of Georgia: Tbilisi, Georgia, 2018.

43. National Statistics Office of Georgia. Geostat Agriculture of Georgia, Statistical Publication; National Statistics Office of Georgia: Tbilisi, Georgia, 2020.

44. GeoStat National Statistics Office of Georgia (GeoStat), Tbilisi, Georgia. 2014. Available online: https://www.geostat.ge/regions / \# (accessed on 2 October 2020).

45. Bernabé, S.; Stampini, M. Labour Mobility during Transition: Evidence from Georgia. SSRN Electron. J. 2008, 17, 377-409. [CrossRef]

46. Pignatti, N. Demographic Structure, Labor Market Conditions and Stalled Agricultural Development in a Post-Transition Country; Tbilisi State University (TSU): Tbilisi, Georgia, 2017.

47. IFAD. IFAD Results-Based Country Strategic Opportunities Programme 2019-2024; IFAD: Rome, Italy, 2018.

48. Muehlfried, F. Sharing the same blood-Culture and cuisine in the Republic of Georgia. Anthr. Food 2008, Food2008, 3. [CrossRef]

49. Springmann, M.; Godfray, H.C.J.; Rayner, M.; Scarborough, P. Analysis and valuation of the health and climate change cobenefits of dietary change. Proc. Natl. Acad. Sci. USA 2016, 113, 4146-4151. [CrossRef]

50. FAO. Representation in Georgia; Food and Agriculture Organisation of the United Nations: Rome, Italy, 2015. Available online: http:/ / www.fao.org/3/bc305/bc305.pdf (accessed on 22 September 2020).

51. Zubiashvili, T.; Silagadze, L. Some aspects of the Georgian economy at the contemporary stage. Ecoforum 2016, 5, 1-5.

52. Mayfield, L.E.; Bennett, R.M.; Tranter, R.B.; Wooldridge, M.J. Consumption of welfare-friendly food products in Great Britain, Italy and Sweden, and how it may be influenced by consumer attitudes to, and behaviour towards, animal welfare attributes. Int. J. Food Agric. 2007, 15, 16.

53. IFAD. IFAD Dairy Modernisation and Market Access Programme (DiMMA): Final Project Design Report; IFAD: Rome, Italy, 2018.

54. Napolitano, F.; Girolami, A.; Braghieri, A. Consumer liking and willingness to pay for high welfare animal-based products. Trends Food Sci. Technol. 2010, 21, 537-543. [CrossRef]

55. Mounier, L.; Veissier, I. Proceedings of the 6th International Conference on the Assessment of Animal Welfare at the Farm and Group Level; Wageningen Academic Publishers: Wageningen, The Netherlands, 2014; ISBN 978-90-8686-247-4.

56. GeoStat National Statistics Office of Georgia (GeoStat), Tbilisi, Georgia. 2019. Available online: https://www.geostat.ge/en/ modules/categories/196/agriculture (accessed on 10 March 2021).

57. Creswell, J.W.; Plano Clark, V.L. (Eds.) Choosing a Mixed Methods Design. In Designing and Conducting Mixed Methods Research; SAGE Publications: Thousand Oaks, CA, USA, 2006; pp. 58-88.

58. Libakova, N.M.; Sertakova, E.A.; Siberian Federal University. The Method of Expert Interview as an Effective Research Procedure of Studying the Indigenous Peoples of the North. J. Sib. Fed. Univ. Humanit. Soc. Sci. 2015, 1, 114-129. [CrossRef]

59. Avkopashvili, G.; Avkopashvili, M.; Gongadze, A.; Gakhokidze, R. Eco-Monitoring of Georgia's Contaminated Soil and Water with Heavy Metals. Carpathian J. Earth Environ. Sci. 2017, 12, 595-604. 
60. Bakradze, E.; Vodyanitskii, Y.; Urushadze, T.; Chankseliani, Z.; Arabidze, M. About rationing of the heavy metals in soils of Georgia. Ann. Agrar. Sci. 2018, 16,1-6. [CrossRef]

61. Felix-Henningsen, P.; Sayed, M.A.H.A.; Narimanidze-King, E.; Steffens, D.; Urushadze, T. Bound Forms and Plant Availability of Heavy Metals in Irrigated, Highly Polluted Kastanozems in the Mashavera Valley, SE Georgia. Ann. Agrar. Sci. 2011, 9, 110-120.

62. Felix-Henningsen, P.; Urushadze, T.; Steffens, D.; Kalandadze, B.; Narimanidze, E. Uptake of heavy metals by food crops from highly-polluted Chernozem-like soils in an irrigation district south of Tbilisi, Eastern Georgia. Agron. Res. 2010, 8, 781-795.

63. Felix-Henningsen, P.; Urushadze, T.F.; Narimanidze, E.I.; Wichmann, L.; Steffens, D.; Kalandadze, B. Heavy metal pollution of soils and food crops due to mining wastes in an irrigation district south of Tbilisi, Eastern Georgia. Ann. Agrar. Sci. 2007, 5, 11-27.

64. UN Women. Gender Assessment of Agriculture and Local Development Systems; S.C.O.: Beijing, China; A.D.C.: Tbilisi, Georgia, 2018.

65. Oxfam. Barriers for Women in Agriculture Focus Group Research; Oxfam: Nairobi, Kenya, 2015.

66. UNDP. Public Perceptions on Gender Equality in Politics and Businesses; UNDP: New York, NY, USA, 2013.

67. UNFPA. Men, Women, and Gender Relations in Georgia: Public Perceptions and Attitude; UNDP: New York, NY, USA, 2020.

68. FAO. Gender, Agriculture and Rural Development in Georgia, Country Gender Assessment Series; FAO: Rome, Italy, 2018.

69. FAO. Gender Equality, Social Protection and Rural Development in Eastern Europe and Central Asia; Insights from the region: Budapest, Hungary, 2016.

70. Gieseke, D.; Lambertz, C.; Gauly, M. Effects of cubicle characteristics on animal welfare indicators in dairy cattle. Animal 2020, 14, 1934-1942. [CrossRef]

71. Hansson, H.; Lagerkvist, C.J. Identifying use and non-use values of animal welfare: Evidence from Swedish dairy agriculture. Food Policy 2015, 50, 35-42. [CrossRef]

72. Vasseur, E.; Borderas, F.; Cue, R.I.; Lefebvre, D.; Pellerin, D.; Rushen, J.; Wade, K.M.; De Passillé, A.M. A survey of dairy calf management practices in Canada that affect animal welfare. J. Dairy Sci. 2010, 93, 1307-1316. [CrossRef]

73. FAO. Survey Sheds Light on Georgian Farmer Attitudes toward Livestock Traceability. Available online: http:/ /www.fao.org/ georgia/news/detail-events/en/c/1073576/ (accessed on 20 September 2020).

74. FAO. Georgia Gets Ready for Possible Reemergence of Cattle Disease. Available online: http://www.fao.org/georgia/news/ detail-events/en/c/853929/ (accessed on 24 September 2020).

75. ALCP. Better Cheese, Better Work. International Labour Office: Georgia. 2020. Available online: https://www.ilo.org/wcmsp5 /groups/public/---ed_emp/---mp_ent/documents/publication/wcms_746235.pdf (accessed on 24 September 2020).

76. Europe Foundation. Food Safety Regulation in Georgia: Assessment of Government's Reform Efforts in 2016; Europe Foundation: Tbilisi, Georgia, 2016.

77. Europe Foundation. Food Safety Regulation in Georgia: Assessment of Government's Reform Efforts in 2015; Europe Foundation: Tbilisi, Georgia, 2015.

78. Europe Foundation. Food Safety Regulation in Georgia: Assessment of Government's Reform Efforts in 2012; Europe Foundation: Tbilisi, Georgia, 2012.

79. Resolution N 29: Antimicrobial Resistance for 2017-2020 on the Approval of the National Strategy; Government of Georgia: Tbilisi, Georgia, 2017; p. 7. Available online: https:/ / www.ncdc.ge/Handlers/GetFile.ashx?ID=cfaca9b4-17f5-417b-bdad-a37f20209920 (accessed on 20 September 2020).

80. Belay, D.; Yisehak, K.; Janssens, G.P.J. Socio-Economic factors influencing urban small-scale dairy management practices in Jimma town, Ethiopia. Libyan Agric. Res. Center J. Intern. 2012, 3, 7-12.

81. Mlelwa, J. Dairy Cattle Milk Productivity in Namtumbo District Council. Ph.D. Thesis, Mzumbe University, Morogoro, Tanzania, 2018.

82. Europe Foundation. Food Safety Regulation in Georgia: Assessment of Government's Reform Efforts in 2017; Europe Foundation: Tbilisi, Georgia, 2017. 